\title{
Grasping intersubjectivity: an invitation to embody social interaction research
}

\author{
Hanne De Jaegher ${ }^{1,2}$ - Barbara Pieper ${ }^{3,4}$. \\ Daniel Clénin $^{3,5,6}$ - Thomas Fuchs ${ }^{7}$
}

Published online: 8 July 2016

(C) The Author(s) 2016. This article is published with open access at Springerlink.com

\begin{abstract}
Underlying the recent focus on embodied and interactive aspects of social understanding are several intuitions about what roles the body, interaction processes, and interpersonal experience play. In this paper, we introduce a systematic, hands-on method for investigating the experience of interacting and its role in intersubjectivity. Special about this method is that it starts from the idea that researchers of social understanding are themselves one of the best tools for their own investigations. The method provides ways for researchers to calibrate and to trust themselves as sophisticated instruments to help generate novel insights into human interactive experience. We present the basics of the method, and two empirical studies. The first is a videostudy on autism, which shows greater refinement in the way people with autism embody their social interactions than previously thought. The second is a study of thinking in live interactions, which provides insight into the common feeling that too much thinking can hamper interaction, and into how this kind of interactional awkwardness might be unblocked.
\end{abstract}

Hanne De Jaegher

h.de.jaegher@gmail.com; http://hannedejaegher.wordpress.com

1 IAS-Research Centre for Life, Mind \& Society, Department of Logic and Philosophy of Science, University of the Basque Country, Donostia, San Sebastián, Spain

2 Centre for Computational Neuroscience and Robotics, and Centre for Research in Cognitive Science, Department of Informatics, University of Sussex, Brighton, UK

3 PRISMA Projects, Munich/Berne, Germany \& Switzerland

$4 \quad$ FVD Feldenkrais-Verband Deutschland e.V., Munich, Germany

5 SFV Schweizerischer Feldenkrais-Verband, Berne, Switzerland

6 Switzerland University of Arts, Berne, Switzerland

7 Psychiatric Department, University of Heidelberg, Heidelberg, Germany 
Keywords Experience of interacting $\cdot$ First-person methods $\cdot$ Second-person methods Embodied methodology $\cdot$ Embodiment $\cdot$ Enaction $\cdot$ Researcher as instrument $\cdot$ Practical phenomenology $\cdot$ Autism · interacting and thinking · Participatory sense-making · PRISMA

"Who is the expert when it comes to understanding people-the detached
scientist or the ordinary person in everyday life?"

(Vasu Reddy 2008, p. 5)

\section{Introduction}

If we were to 'ask the expert' what it means to understand someone, who would this expert be? A taxi driver, a child, a professor of psychology? Each of them can answer questions about how it feels to connect with someone, or how they know that their friend is upset. We may not always think we can easily put it into words, but we are very experienced at intersubjectivity, just by virtue of our being so involved in it from the beginning of life, each in our own ways and also in many ways we share with others. Intersubjective experience resides in our embodied habits, attitudes and comportments, and plays out in the ways we interact with others. It is in the way the taxi driver cruises through traffic; the small child's eyes sparkle while he flirts with his grandmother over a bowl of tomato soup; the psychology professor teaches her students about connection in the way she engages them through the inflection of voice, gesture, and gaze.

These bodily experiences of interacting are the stuff of understanding each other and of understanding the world together - in short, of intersubjectivity. We characterise intersubjectivity as the meaningful engagement between subjects (cf. Reddy 2008). We consider subjects to be animate, bodily, affective, minded beings, in their various social and societal contexts (in the sense advocated by e.g. Sheets-Johnstone 1999). We are not merely referring to intersubjectivity as the co-existence and mutual necessity of various first-person perspectives, but rather of perspectives that are influenced by and co-created by more than one subject. That this is not the sum of two individual perspectives is clarified by the idea that interactions can take on an autonomy of their own and that interactions as such influence, form and transform their participants (De Jaegher and Di Paolo 2007; Di Paolo 2015). When we take this autonomy of interaction processes into account, intersubjectivity is characterized as participatory sensemaking: the embodied, interactive coordination of sense-making (De Jaegher and Di Paolo 2007). It is this phenomenon that we aim to investigate further here, specifically focusing on the experience of interacting and how it modulates social understanding (De Jaegher 2015).

To lay people, it is often obvious that how we interact and move matters - that our living, lived bodies play a great role in understanding each other. Whether academic research also takes embodied interactions as essential to intersubjectivity can have reallife consequences and impact, because research leads to guidelines and policies, and is intricately connected to the sensitivities of a society (Reddy 2008). 
For these and other reasons, cognitive scientists and philosophers of mind are increasingly questioning individualist, cognitivist approaches to social interaction, and are instead beginning to take account of the body and of interaction processes between embodied subjects (Reddy and Morris 2004; Gallagher 2005; Ratcliffe 2007; De Jaegher and Di Paolo 2007; Schilbach et al. 2013). Embodied and situated approaches to explaining social understanding now seem, to many scientists and philosophers as well, reflective of our intuitions about social understanding.

However, how is it with these intuitions? What do we know about the first-hand experience of bodily interacting and its role in understanding each other and the world together? Can we investigate this experience? If so, how? Can we get a philosophical, empirical, scientific, and existential grasp on the role of interactive experience in social understanding?

We think it is possible. In this paper, we introduce a method for investigating the experience of interacting. More specifically, we propose an empirical, embodied method for the study of interactive experience and its role in social understanding.

We start by introducing the need for and place of a practical phenomenology of interactive experience in the current research landscape. Then we introduce the method we devised, called PRISMA (section 3). We explain its embodied methodology and concepts, including an invitation and a guideline for the reader to try out the method (appendix). We also present two sets of findings (section 4), one on autism, based on a video analysis, and one on the relation between interacting and thinking, based on live contact improvisation. Finally, we reflect on the method and its implications, such as its capacity to detect unexpected aspects of the 'in-between' in interactions, and its potential to enrich the science of intersubjectivity (sections 5 and 6).

\section{The need for a practical phenomenology of interactive experience}

An empirical phenomenological method for studying interactive experience is needed and the time is right for it, for several reasons.

We are currently witnessing an interactive-experiential turn in social cognition research, and an explosion of studies on the dynamics of embodied interactions between people, in fields ranging from neuroscience, over psychopathology and psychotherapy, to linguistics (Dumas et al. 2011; Ramseyer and Tschacher 2008; Di Paolo and De Jaegher 2012; Schilbach et al. 2013; Timmermans and Schilbach 2014; Fusaroli et al. 2014). At the same time, there is increasing recognition of the indelible role that the subjective experience of interacting - of interpersonal connecting - plays in how we understand each other (Pfeiffer et al. 2014). That what it feels like to connect with others makes a great difference to interpersonal understanding has been beautifully illustrated, often in developmental psychology, against the backdrop of a rich history of investigating how infants move and participate affectively and intentionally in conversations with their mothers (Stern 1977/2002, 1985; Trevarthen 1977; Bateson 1979; Bullowa 1979; Hobson 2002; Malloch and Trevarthen 2009; Delafield-Butt and Trevarthen 2015), but also of psychopathology and psychotherapy (Watzlawick et al. 2011; Beebe and Lachmann 1998; Stern 2004). Nevertheless, however moving such studies are, standard cognitive science is still often embarrassed about or averse to 
anything alluding to the personal or the subjective, ${ }^{1}$ making it so that this kind of research remains in need of defense (Reddy 2008).

Endeavouring to understand personal, subjective experience has a checkered history in psychology and the cognitive sciences. It is impossible to think about it without bringing to mind the dreaded 'introspection'. But introspection's bad name may be undeserved, as Jack and Roepstorff (2002a, b, 2003) have persuasively argued. They suggest that the scepticism may be more cultural and historical than based in the logic and results of experimentation in cognitive science and psychology. They observe that introspection is present at every step of experimentation, from the conception of the experiment, over piloting and refining it, to interpreting the results (2002a, p. 333; see also Petitmengin and Bitbol 2009). ${ }^{2}$ Several studies, moreover, show not only that introspective data can be accurate, but also very useful in refining our understanding of, for instance, synaesthesia (Harrison and Baron-Cohen 1997), epilepsy (Le Van Quyen and Petitmengin 2002), or trauma remediation (Payne et al. 2015). Thus, individual subjective experience clearly plays its role in science, both in methodology, albeit most often implicitly, and in its findings. This is in line with enactive cognitive science, which considers subjective experience an essential element in its research toolkit, as well as an entirely legitimate object of investigation (Di Paolo et al. 2010; Thompson 2001, 2007). But it is not yet an accepted element of mainstream cognitive science.

If we want a better grasp of social understanding, we need ways to study its experience. For individual experience, practical, bodily engaged, empirical ways of investigating have been developed. Varela, Depraz and Vermersch call this practical phenomenology (Depraz et al. 2003), and similar work has been done by, e.g. Varela (1996), Varela and Shear (1999a), Shusterman (2008), Gendlin (1962/1997), Stern (2004), Van Manen (1990), Ihde (2012), Petitmengin (2009), and others (see also Froese et al. 2011; Høffding and Martiny 2015). What connects all this work is a common concern with lived experience as it plays out in our daily lives, in relation to our capacities for understanding the world, our social and cultural practices, as well as our intersubjective and ethical engagements. The frame within which this happens is that of a 'mutual circulation' between cognitive science and phenomenology (Varela et al. 1991; Varela 1996; Gallagher 1997), in which subjectivity and experience play the vital role that they also have in the everyday doings of living, sentient, sense-making beings (Thompson 2005), as well as can be scientifically grasped (Petitot et al. 1999).

But practical or empirical phenomenology has so far not focused much on interactive experience. This is remarkable, because the relation between intersubjectivity and the study of experience is interesting and complex in itself. This relation is, for instance, present in the methods of science, where intersubjectivity forms an essential aspect of the research process. Only by engaging peers can the value of a piece of research be

\footnotetext{
${ }^{1}$ See Peter Hobson's recounting of how, in the publication of a study on how children with autism greet and say goodbye, he was at first asked to just call it a study of the - supposedly experientially neutral - behaviour of the children, not their engagement (Hobson and Lee 1998; Hobson 2002, chapter 2).

${ }^{2}$ This is echoed as well in Hans Jonas's remark on the close connection between personal experience and research: "As concerns 'understanding,' the cognitive approach of the humanities, it is clear that 'personal experience,' understood as empathy with the object - itself the concrete embodiment of experience - is an indissoluble part of the intellectual process from start finish, pervading the entire interpretation" (Jonas 2002, p. 28). Polanyi avows that the same is true for the natural sciences, where "no scientific work could ever be accomplished and no scientific statement could be asserted" without "an essential personal participation of the scientist even in the most exact operations of science" (Polanyi 1958, p. 20).
} 
determined. Even data should be what is commonly called intersubjectively validated'. This is of course no less the case for phenomenological research, and in many of its guidelines, intersubjectivity features prominently as one step in the process (Varela and Shear 1999a; Gallagher and Zahavi 2008, Depraz et al. 2003). This kind of intersubjectivity refers to the need and practice of checking and comparing results against other people's reported experiences. It is, indeed, one of the senses of intersubjectivity we use in this paper, and it is in this form also central to our own methodology.

Clearly, intersubjectivity and the study of experience are inextricably linked, even if more knowledge about both is paramount to making further progress. Thompson, for instance, argues that "human experience depends formatively and constitutively on the dynamic coupling of self and other in empathy" (2005, p. 263), while on the other hand Vermersch suggests that we need a better theory of intersubjectivity if we want to understand experience better (Vermersch 1999, p. 41). In presenting our method here, we aspire to contribute to an improved theory — and empiry! — of intersubjectivity that can support and inform basic experience research.

So, in view of the development of an increasingly sophisticated science of intersubjectivity, there is a need for a suitable method to study interactive experience. This is what we present in this paper. The method is called PRISMA, and can be summarized as the systematic unfolding of interactive experience. PRISMA has three main characteristics: it uses a systematic protocol for investigating the experience of interacting, it is based on an embodied methodology and concepts, and it invites researchers to use themselves as both research instrument and subject of their own investigation. The paper is constructed in such a way that readers are guided into the method so that they can start, if they wish, to apply it in their own studies. Examples, vignettes, and tables serve as illustrations of applications made, and as templates for readers' own embodied interactive studies.

The name PRISMA is no accident. A prism refracts light in its constituent spectral colours and in this way makes it possible to take different perspectives on the light while maintaining its characteristics. Because of the different colours, what was perceived until now — the light — changes and complements itself. A prism thus enables an unfolding, a 'fanning out' or unraveling, of the light into its different colours. PRISMA aims to do something similar for the experience of socially interacting (Pieper and Clénin 2012, p. 17).

\section{PRISMA}

A typical PRISMA experiment takes the form of a workshop that may last from a few hours to two days. Note that 'experiment' here does not mean the same as in the classical, natural science case of an event studied under laboratory conditions. Rather, an experiment comprises a whole PRISMA session. While it does not take place in a lab, it is an empirical enquiry that follows certain methods and protocols (see also Van Manen 1990). The optimal number of participants is between 6 and 20. A workshop usually begins with a short series of body exercises, designed specifically for each 
workshop in order to 'tune' or 'calibrate' the participants for the investigations during the workshop. ${ }^{3}$

A workshop proceeds through several short sessions where participants are asked to perform a particular short interaction, usually in groups of three (two interactors and an observer), e.g. helping someone into their coat. Immediately after each interaction, all participants are asked to respond individually to a prompt, designed specifically to register a particular element of their experience of that interaction (examples follow below, see e.g. Table 1). Participants are encouraged to do this quickly (as immediately as possible) and succinctly (they are given only the space of a Post-it note).

Each interaction is repeated several times, so that participants take on different roles (giving or receiving the coat, observing the interaction) and answer a different prompt. Each time, participants focus on a singular aspect of the interaction: on themselves (self-perception), on the other (other-perception), or on what happens between them (the in-between). Moreover, they are asked to do this in different modes of perception: sensing (focusing on bodily sensations, e.g. breathing, posture), feeling (emotional state or process), or thinking.

Throughout the workshop, the participants' notations (on Post-its) are systematically gathered on a matrix (a grid on a sheet of paper, e.g. Table 1). The matrix guarantees that the different perspectives are registered in an ordered way and makes it evident that all collected notations are aspects of one and the same interaction investigated. This format provides an organized visual overview of the whole process, i.e. of the different results in terms of the roles, perspectives, and modes that each participant has gone through, represented along its axes. The notations gathered on the matrix allow participants to go back and forth between the data and the experiences during the workshop, and to compare and progress on the knowledge and insights gained on the social interaction.

The process also contains additional strategies for further unfolding aspects of the interaction under investigation. Notations may be taken as a starting point for another run-through of the interaction. For instance, in a process called a conFiguration, the participants select a particular notation. Usually, this is something that is in some way particular, meaningful, or salient to the practiced interaction. This is then used as a 'catalyst' or perceptual 'filter' to be applied while further processing. To illustrate this process, say the participants select "there was some shyness". Once chosen, the next step is to re-investigate the interaction while each participant re-produces in herself in some way the selected statement "there was some shyness". On the basis of this, new notations are gathered for further refinement and comparison. In this way, the initially detected "shyness" is refined: it may be revised, changed, or confirmed by doing the modified run-through.

\footnotetext{
${ }^{3}$ With regard to the body exercises, we base them on the Feldenkrais method (e.g. "Awareness Through Movement"). However, any valid basis can be used. The exercises need to be well-thought-out so as to prepare, tune, or calibrate the researcher for the specific tasks at hand during the experiment. The underlying principle is that, just like with other kinds of instruments (microscopes are adjusted, pipettes are cleaned, violins and pianos are tuned), the researcher as lived bodily being prepares herself for the task at hand (another example is the principle of yoga, the movement sequences of which serve to prepare the body for sitting meditation. As well, movement analysts, for instance in dance movement therapy studies, are trained in the movement repertoire they will analyse).
} 
At specific points in the workshop, participants are also given time to discuss the findings based on the data collected. These discussions are led by the workshop facilitators (so as to remain on topic), who also take notes on the workshop process and the discussions. The notations, discussion notes, and matrices are kept and later transcribed anonymously. Copies are stored digitally for future reference and can be sent to the participants for further examination after the workshop. Other formats than live interactions are also available, for instance, analysing a video of people interacting.

We will now explain the three main characteristics of PRISMA: its systematic protocol for investigating the experience of interacting; its specific, continually developing embodied methodology and set of concepts; and its participative aspect, i.e. an invitation for researchers to use themselves as research instrument and subject in their own investigation.

\subsection{A systematic protocol for investigating the experience of interacting}

A PRISMA process unravels, unfolds, or refracts interactive experience by submitting it to a systematically structured investigation. Live, real-time, everyday interactions are complex, multilayered, multi-timescale processes, with a great number of elements at play in them. In a PRISMA process, we gain insight into the experience of interacting by systematically shifting perspectives on it.

Participating in a PRISMA workshop means approaching interactive experience through an experiential grid of dynamic, bodily, self-enacted differentiations. We call these differentiations references of perception (Pieper and Clénin 2012). The main references of perception are self-perception and other-perception on the one hand, and the modi of sensing, feeling, and thinking on the other. In each round of interacting, experience is approximated or 'grasped' by running through these references of perception one by one. In self- and otherperception, participants are prompted to focus first on perceiving themselves, then the other. The 'other' is either the other person, or the interaction process as such, i.e. what happens inbetween the interactors. Sensing refers to sensations of, for example, differences in temperature and light, spatial positioning such as contact with the floor, spatiotemporal localization, rhythm, and so forth. In feeling, sensations are affectively valued in their connection to the situation. For example, shivering for fear, or the increased heartbeat of fear or of joy (Fuchs and Koch 2014). Thinking is more of a reflective form of sense-making, including imagining, evaluating, reminiscing, wondering, as well as reasoning. The workshop facilitators hand out the prompts to guide the participants through the unfolding of their experience along these references.

The references of perception are generated step by step, and ongoingly compiled in the matrix. The matrix illustrates our hypothesis that the intersubjective phenomena grasped via the references of perception in principle happen at the same time. The notations as laid down in the matrix provide a bird's eye view of the experience of interacting as unravelled or refracted throughout the workshop process. Table 1 shows a simplified version of a matrix, in which the participants focus on sensing.

To anticipate some possible objections: we are aware that the experience of interacting is modified by the PRISMA process. This is an oft-made criticism of any method that investigates experience (see e.g. Varela and Shear 1999b, Depraz et al. 2003). Of course, the first response to this is that it is impossible to investigate any phenomenon, even those studied in physics, without somehow changing it in the 
Table 1 An example of a PRISMA matrix for recording references of perception. Horizontally, the rows indicate the roles: interactors 1 and 2 (rows 1 and 2 respectively), and the observer (row 3). Vertically, the columns indicate the reference of perception, self-perception (SP, column 1) or other-perception (OP, column 2). This simplified matrix allows to gather the approximations made in two rounds of interacting, in which each participant stays in one and the same role (interactor 1, 2, or observer). In the first round, they sense in the mode of self-perception, and fill out their prompt (shown in column 1), and in the second round, that of otherperception (shown in column 2)

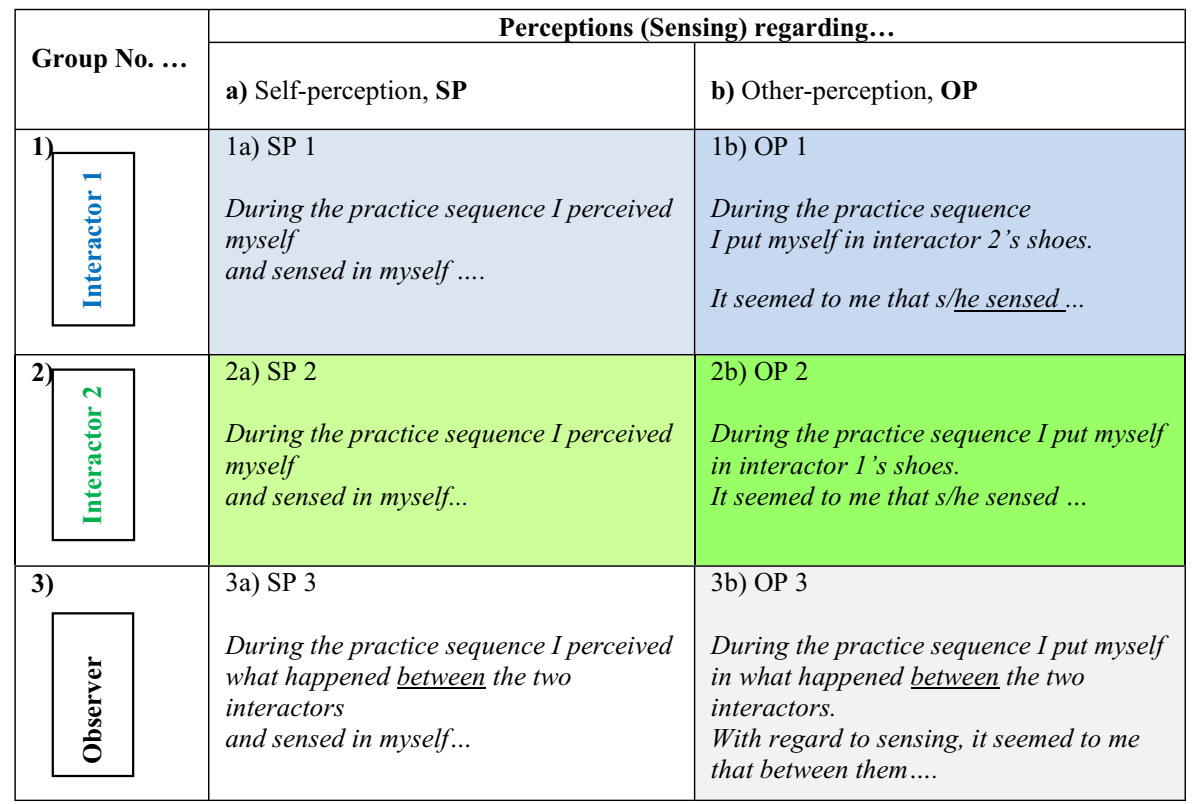

process. But let's take seriously the issue in the realm of investigating experience. Experience is not a static thing in daily life. Attending to it changes it, also as we live it every day. It is inherent to experience that it is dynamic as it is lived, as we move around in and understand our world, and certainly under awareness of it. Therefore, to investigate experience $i s$ to investigate its transformation - and perhaps all the more so in social interactions.

For this reason, the matrix used in PRISMA records, traces, and makes accessible to inspection the development of and changes in the subjective experience as researchers ongoingly participate in the interactions. This makes the investigation verifiable and reproducible. Furthermore, a PRISMA process includes the possibility of purposefully changing the experience, through the conFiguration process. Investigating particular changes in the experience of interacting acknowledges and operationalizes the phenomenon of the modulation of experience under its inspection.

Another issue for reflection is the question of why we differentiate the prompts for investigating interactive experience along self- and other-perception, sensing, feeling, and thinking. These chosen references of perception are dynamic elements in the overall PRISMA research, which have been crafted and developed over years of building the method, based on the professional backgrounds of the method's main 
developers (authors 2 and 3). These include subject-oriented sociology (Beck and BeckGernsheim 1996; Jurczyk et al. 2016, Pieper 1983, 1997), and the Feldenkrais method (Feldenkrais 1947, 1981). The methodology of shifting perspectives is basic to both: in subject-oriented sociology in its method, and in Feldenkrais in its practice. Subject-oriented sociology studies the impact of subjects on society and of society on subjects, as they play out in everyday experience and interactions. Of special interest here is the 'in-between' that makes 'togetherness' or social coherence in societies work (Bolte 1997; Pongratz and Voß 1997). The Feldenkrais method is a movement-based embodied learning practice, developed by the physicist Moshe Feldenkrais (Pieper and Weise 1997; Pieper and Clénin 2012; Buchanan 2012; Kimmel et al. 2014; Verrel et al. 2015). Feldenkrais emphasised the crucial importance of sensation and movement in the arising, stabilisation, reinforcement, and changing of behaviour. He used the meaningfulness of movement to initiate development of the client's self-image as involved in everyday activities in its tactile-kinaesthetic, emotional, and mental aspects. In this process, movement serves as a tool for gaining awareness in action as a capability for improving life.

While most (subject-oriented) sociologists mainly study agents in relation to others (other-perception), the Feldenkrais method focuses more on self-image, self-observation, and self-awareness (self-perception). PRISMA combines these differences of focus into a methodology for investigating the experience of embodied interactions between societally contextualized subjects (also Clénin and Pieper 2012, p. 3-6). In PRISMA, the references of perception are hypotheses that are tested time and time again (cf. the methodological "open exploration" of Depraz et al. 2003, p. 17). They are often spontaneously questioned and debated by participants during workshops, and taking into account these questions, critiques, and insights - their use and presentation can be adapted in following workshops.

In sum, the differentiations we use are grounded in both theory and practice as well as supported by independent experimentation, and they are continually open to principled modification and improvement. Our main goal with them is to enable researchers to embody the investigation of intersubjectivity.

\subsection{PRISMA's embodied methodology and concepts}

When we invite researchers to embody research on the experience of social interaction, we invite them to become aware participants of the interactions they engage in while investigating them. PRISMA enables this process through its embodied methodology and concepts.

In order to make intersubjectivity 'graspable' and to operationalize its investigation, we need characteristics of social action that are concrete and 'handy' so as to be accessible to experience and testable in a research setting. For this, we employ three characteristics of social perception: its spatiality, its sociality, and its modalities of sensing, feeling, and thinking.

Social relatedness is necessarily impacted by spatio-temporal conditions. While relating to oneself, to others, and to objects, people are naturally affected by and employ references in space and time - whether they know about it or not (Fuchs 2000). Investigating social interaction with PRISMA, we ask from where, towards where, towards whom, what for, and how people experience, observe, conceive, and perceive their environment, themselves, and others. We call this dynamic directedness in action and interaction - a term that combines spatio-temporal-social 'direction' and 'relatedness' as integral components of social encounters. What PRISMA offers is a method to unfold what happens here, so as to better grasp how 
experiencing the situation arises. We will illustrate and describe the coherencies between spatiality, sociality and modalities step by step, along a well-known example. ${ }^{4}$

Most of us are familiar with the situation: In a corridor or a busy pedestrian street, two people approach each other from opposite directions. As they try to get past each other, they get stuck, repeatedly stepping in front of each other.

Firstly, this 'corridor example' illustrates the role of spatiality in interaction. Spatiality may impact or even co-condition this social encounter's configuration. Just to mention some aspects:

- Direction: Both protagonists have to walk towards each other in opposite directions - not parallel to each other, neither in a bow, nor approaching from behind. Escaping movements by both walkers only happen sideways, no turning backwards.

- Location: A too narrow corridor will initiate a predictive evading, a too broad one easily enables parallel passing. A rather empty and wide pedestrian street provokes less collision. Spatial constraints must at least allow stepping out to both sides equally.

- Differences in experiencing spatial orientation: From an observer's third-person spatial perspective both walkers step out to the same side. The interactor, from her first person perspective, orients herself from her body in space. The collision-encounter only evolves if both interactors, from their subjective perspective, do not step out to the same side, but one sideways to her right, the other to her left and back and then to the other side and so forth. Moreover, they remain in an upright frontal position to each other until something interferes.

In our research we develop and apply an embodied stance. This means recognizing people in their animate lived nature, and considering them as lived bodies moving in time and space in a three-dimensional field of gravitation. We systematically incorporate spatiality in particular directions and their relatedness to behaviour ('directedness') in our research: from where to where is perception initiated or happening in (inter)action? Elaborated both methodologically and conceptually, directedness provides us with a unique tool for research. ${ }^{5}$

Secondly, we can unfold the corridor example further along the lines of sociality. How will the two walkers experience this peculiar situation? Each of them realises what is going on only the very moment it happens - otherwise they would have avoided it. Walker A notices the other, perceives her presence above all as an obstacle. Relatedness takes place from A towards B, and likewise from B towards A. They cannot avoid noticing the sudden 'obstacle' in front of them. Each of them, maybe less evidently, will also become aware of herself. Walker A may incidentally check her own position and feel an urgency to get out of the way. Likewise interactor B also refers to herself, to her own position, not only to the other. Amazingly, and characteristic of this encounter, both interactors, while stepping out

\footnotetext{
${ }^{4}$ This example is often used to explain the idea of the autonomy of the interaction in participatory sensemaking theory (e.g. De Jaegher and Di Paolo 2007, p. 493-494), where the focus is on the coordination dynamics and on illustrating the idea that interactions can in part determine individual intentions. Here, we give it a few further dimensions.

${ }^{5}$ We wonder why spatiality in its fundamental significance for action is often neglected. "Space has never been central to sociological thought" (Lechner 1991, p. 195) - not even for Berger and Luckmann 1966 (see Pieper and Clénin 2012, p. 13). Maybe conditions of gravitation are so deeply embedded in us that we take them for granted - until we lose our balance and suddenly realise its evidence. Spatiality is addressed in phenomenology (e.g. Fuchs' "lived space", 2000, 2007; and Merleau-Ponty 1945/2012 on space as primordial expressions of "being-in-the-world"), in human geography (Hubbard and Kitchin 2004), in sociology (Simmel 1908 , on the spatial projection of social forms; Löw 2008 on the constitution of space), and in the science of touch (Grunwald and Beyer (2010).
} 
of the constraint situation, move sideways at the same time in a way like dancers do, together, one to her left, the other to her right side. The two walkers unintentionally remain in their frontal bodily relatedness, in what happens between them in interactional coordination, and thus remain an obstacle to each other as long as this dynamic continues.

The example illustrates how, in PRISMA, social encounters are differentiated into the self-perception (SP) and other-perception (OP) of each individual involved in the interaction. Emphasizing its mutuality, we call this dynamic the dual aspect of perception (Pieper and Clénin 2012, p. 11). In principle, we consider the four references within an interaction process (each interactor perceiving herself and perceiving the other $=$ four references in total) to be given per se, embodied, mutual, fundamentally socially constituted, carrying equal weight, and taking place at the same time (Pieper and Clénin 2012, p. 15; Küchenhof 2014). While we take the existence of these references of perception as a starting point of our research, we at the same time ongoingly test them.

In addition we consider what happens between the interactors: 'the in-between'. On the basis of the concepts of participatory sense-making (De Jaegher and Di Paolo 2007; De Jaegher 2009; Fuchs and De Jaegher 2009; Cuffari et al. 2015), we detected that the in-between is a third basic component of equal weight impacting the social encounter, and we enlarged PRISMA's concepts and methodology accordingly. Findings with the PRISMA paradigm can give insights into the role of these references of perception in intersubjectivity (as we illustrate in section 4).

Now let's address the corridor example a third and last time. We also want to know in which way the walkers experience each other, themselves and what happens between them. For instance, walker A might sense her physical involvement in moving sideways and feel her annoyance in being hindered by B. Walker B may think walker A will move first, and that she will just need to wait to get out of the situation. But A hesitates, and then her next move again mirrors walker B. Maybe A's annoyance increases: how come that something in the encounter drives it forward against their deliberate intentions to get out of it? Then suddenly she finds herself turning backwards and extending her arm in a gesture of 'after you'.

Thus, we further differentiate perception into three modalities: sensing, feeling, and thinking. These have been chosen quite pragmatically, and they can be distinguished from each other in lived bodily experiencing. Feldenkrais discerned, described, and referred to them in his practice, indicating that the three modalities always involve movement and are viewed as equal aspects of action (Feldenkrais 1972, 12, 31; Pieper and Clénin 2012, p. 16). The references of perception are also borne out in independent practical phenomenology research. Hurlburt's work using experience sampling, for instance, seems to consistently find sensing, feeling, and thinking to be separable aspects of awareness (Heavey and Hurlburt 2008; Hurlburt et al. 2009), lending support to the suitability and adequacy of PRISMA's references of perception.

Finally, a note on the notion of embodiment, a term so often used nowadays that it may start to lose sense. One of its sharpest critics is Maxine Sheets-Johnstone, who has again and again rallied against the trend of 'embodying'. She worries that embodied accounts of mind and cognition neglect what she calls "animate experience," and is concerned that the use of the word 'embodied' and its variations does not capture the dynamic "synergies of meaningful movement created by animate organisms" (2015, p. 23). When we use the word here, our invitation to 'embody' intersubjectivity research is in line with SheetsJohnstone's proposal, and departs from the ones she criticises. To embody research is to explicitly take the role of the animate body into account. The PRISMA method does this in 
the bodily tuning of the researchers at the beginning of a workshop, and in the different references of perception, employing self- and other-perception, as they happen in sensing, feeling, and thinking. We think the term 'embodying' is useful precisely as an invitation for researchers to become aware of the animate, concerned, meaningful kinaesthetics of organisms interacting with others. In a way, thus, we invite researchers, like SheetsJohnstone does, to let theory be enlightened by jumping into the deep end of interacting, using PRISMA's systematic research tools.

\subsection{Participate: researchers use themselves as research instrument and subject in their investigation}

In PRISMA, the interacting researcher is an instrument in her own research. She is both and at the same time subject and object of the investigation. She is a lived body, a bodymind, an animate organism in interaction with others. She is always directed towards something and relating to something, and this is what PRISMA investigates. Important in this is to trust, build, and involve researchers' capacities for using their own lived sociality during the investigation of a particular social interaction. Workshop participants engage themselves as embodied instruments for stepping directly into the research process, instead of maintaining a distant view onto the research topic.

In the live-interaction version of prismatic experimentation, participant researchers are subject and object within the same research process. For example, they engage in a short contact improvisation while, at the same time, investigating and detecting aspects of intersubjectivity going on in this process. Here, the chosen social interaction is performed in situ, in a first-hand face-to-face setting (see section 4.2). In the second kind of PRISMA workshop, researchers analyse video-recorded social interactions. Here, researchers are the subject, but not the object of the investigation. They direct themselves towards the research object - the video - and also towards their own and their co-researchers' embodied experiences: sensations, feelings and thoughts coming up while viewing and processing the video. Here, the chosen social interaction is fixed in the past: it is a second-hand social interaction investigated face-to-face, i.e. with the other researchers investigating the video (see 4.1).

\subsection{An invitation to try out the method}

PRISMA allows to test assumptions and intuitions about intersubjectivity and its experience that are not normally tested. But before presenting some of our empirical work, we invite the reader to try out for yourself a short PRISMA process. After all, the point of this work is not just a presentation of methodology, concepts, and findings, but also the experience and its transformative effects, itself. You will find the invitation in the appendix.

\section{Findings}

In this section, we present some results from our empirical work, conducted in two different workshops. ${ }^{6}$ In the first one, we analysed a video of two children with autism,

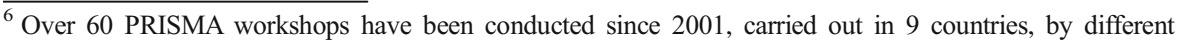
moderators (Clénin and Pieper 2015).
} 
and in the second, we investigated the relationship between thinking and interacting in live contact improvisation.

Before presenting these, we reflect briefly on the nature of empirical experience research and what can be considered its outcomes. As van Manen notes (1990), speaking of 'data' is misleading in human experience research because of connotations with the quantitative efforts of positivistic psychology and social sciences, and the natural sciences. Nevertheless, investigating experience does involve collecting what is 'given,' even if anything 'given' is not identical to the experience itself, but already the result of a transformation of experience. The best thing one can do is to accept this after all, "[w]ithout this dramatic elusive element of lived meaning to our reflective attention phenomenology might not be necessary" (Van Manen 1990, p. 54).

PRISMA makes use of approximations. An approximation is the activity of apprehending an experience through a particular perceptual reference (see section 3.1), and noting down what is then given, as immediately and succinctly as possible. These notations can be considered the initial 'data'. At specific points in a workshop process, the data gathered so far can turn into 'interim findings' to be further processed. The intermediate findings are in this way increasingly refined. They go from individual approximations of experience, through transformations in various kinds of group work (e.g. searching for similarities, conFiguration), to emerging and identifiable regularities or tendencies.

These regularities and tendencies, found by the workshop participants during the research, can be considered the results or findings of a specific workshop, as they represent the deepened insights into the specific issues investigated in that workshop. These outcomes can then be put into critical dialogue with existing theories, concepts, and hypotheses, as well as results from other empirical research.

We would like to note also that outcomes do not just consist of the tendencies and regularities found. Another important result are the ways in which participants change through taking part. The result of a PRISMA process (and similar kinds of practical phenomenology, see e.g. Van Manen 1990), is not just enhanced knowledge or deeper insight into an area of experience, but also - inevitably - the transformation of this experience. This includes both the transformation of the experience itself, and logically - the transformation of the subjects of this experience: the participating researchers (Kordeš 2016; De Jaegher 2016).

\subsection{Friends with autism}

The first workshop-experiment took place at the University of Heidelberg, in July 2009, and lasted one day. We analysed a video fragment, taken from the publicly available documentary Make Me Normal. ${ }^{7}$ The video featured Roxanne and Liam, students of a London school for young people diagnosed with autism

\footnotetext{
${ }^{7}$ Directed by Jonathon Smith, this documentary appeared in the TV series Only Human on Channel 4, UK, on 2nd of June 2005. (The segment we used was available at https://www.youtube.com/watch?v=QLp8oh6hUTk $(3.36-4.40)$, but has unfortunately recently been taken down by the user.) We muted the video in this workshop, so that participants could focus better on embodiment rather than on what was said in the video (though a different PRISMA investigation could also include the video's sound).
} 
(this information was given to the participants prior to starting the videoanalysis). Six participants took part in the workshop, and worked together in groups of three throughout. All were academics, between thirty and fifty-two years old, four females and two males, working in the fields of psychology, psychiatry, and philosophy, three of them were $\mathrm{PhD}$ students, one post-doc, and two professors.

First off during the workshop, the participants viewed the video a first time without a specific prompt. This first approximation was more or less unspecific and used as a foil for comparing the initial and final approximations at the beginning and end of the experiment (the 'before and after'). The question for the participants at this stage was simply: "What did you observe during the video sequence?" The initial approximations are presented in Table 2.

After this, the central part of the experiment was performed. Participants viewed the video 18 more times over the course of the day, making approximations based on specific prompts, one by one, in a structured and guided process, interspersed with breaks, body exercises, and discussions.

The notations from these 18 approximations form what we call the 'full set', that is, the set containing every chosen perspective on the material. The approximations consisted of: self-perception while observing Roxanne, Liam, and the in-between (SP), other-perception while observing Roxanne, Liam, and the in-between (OP), and each of these in the modalities of sensing, feeling, and thinking (yielding 108 notations in total). Immediately after each viewing, participants concisely noted down their first impression on a Post-it. These

Table 2 Initial approximations, ordered per group. Top row: results of group A, bottom row: results of group B. (The participant numbers were not given per group, that is why they are not ordered numerically.)

\begin{tabular}{|c|c|c|c|}
\hline $\begin{array}{l}\text { Approximations } \\
\text { Group A }\end{array}$ & Participant 4 & Participant 3 & Participant 5 \\
\hline $\begin{array}{l}\text { First } \\
\text { approximation: } \\
\text { (based on prompt: } \\
\text { "What did you } \\
\text { observe during the } \\
\text { video sequence?") }\end{array}$ & $\begin{array}{l}\text { "Two children who deal with } \\
\text { each other in very different } \\
\text { ways. So, one does something } \\
\text { else (wilder, more demanding), } \\
\text { than the other (gently, rather } \\
\text { careful)." }\end{array}$ & $\begin{array}{l}\text { "An odd attunement, mutual } \\
\text { respect, a lot of action from } \mathrm{R}, \mathrm{L} \\
\text { keeps to himself, she respects } \\
\text { him. Safe together". }\end{array}$ & $\begin{array}{l}\text { "Two young people, who seem } \\
\text { to be friends, in several } \\
\text { interaction situations, with an } \\
\text { idiosyncratic, ambivalent- } \\
\text { seeming exchange of gestures". }\end{array}$ \\
\hline
\end{tabular}

\begin{tabular}{|c|c|c|c|}
\hline $\begin{array}{l}\text { Approximations } \\
\text { Group B }\end{array}$ & Participant 1 & Participant 2 & Participant 6 \\
\hline $\begin{array}{l}\text { First } \\
\text { approximation. } \\
\text { (based on prompt: } \\
\text { "What did you } \\
\text { observe during the } \\
\text { video sequence?") }\end{array}$ & $\begin{array}{l}\text { "Kinds of contact between two } \\
\text { people. } \\
\text { In some way it was about } \\
\text { overcoming boundaries } \\
\text { Delimiting } \\
\text { Playful - fighting". }\end{array}$ & $\begin{array}{l}\text { "Two young people (children), a } \\
\text { girl and a boy, connect. The girl } \\
\text { seems more energetic, she } \\
\text { changes how and what the boy } \\
\text { reacts unsure whether an attack } \\
\text { or friendship is meant". }\end{array}$ & $\begin{array}{l}\text { "A girl and a boy make contact } \\
\text { in different ways all the time. } \\
\text { They like each other." }\end{array}$ \\
\hline
\end{tabular}

(C) Daniel Clénin und Barbara Pieper, PRISMA Projects, Munich/Berne 2015 
notations formed the basis for further processing (conFigurations) during the workshop. In this way, the participants could track — individually as well as in group, and following the workshop protocol - how and in how far their perceptions on the interaction between Roxanne and Liam changed over the course of the experiment.

Below, we present the full set of approximations, ordered by perceptual reference, and concerning Roxanne, Liam, and the in-between in Tables 3a, $3 \mathrm{~b}$ and $3 \mathrm{c}$, respectively.

What emerges here is a unique material on two children diagnosed with autism interacting with each other. Here, the in-between is an integral part of the investigation all over the process. Specified approaches to intercorporality or the in-between in interaction exist (for instance Merleau-Ponty 1945/2012; De Jaegher and Di Paolo 2007; Fuchs and Koch 2014, see also section 2), but it is still not so clear how to empirically grasp its characteristics in conjunction with the two interacting agents' involvements. The prismatic procedure allows to unfold the interaction, here compiled in the full set matrix, and leads to a differentiated picture of what Roxanne, Liam, and the in-between contribute to the interaction.

Table 3a Full set matrix regarding Roxanne. The notated approximations of all participants: self-perception and other-perception in terms of Roxanne, in the three modes: sensing, feeling, and thinking

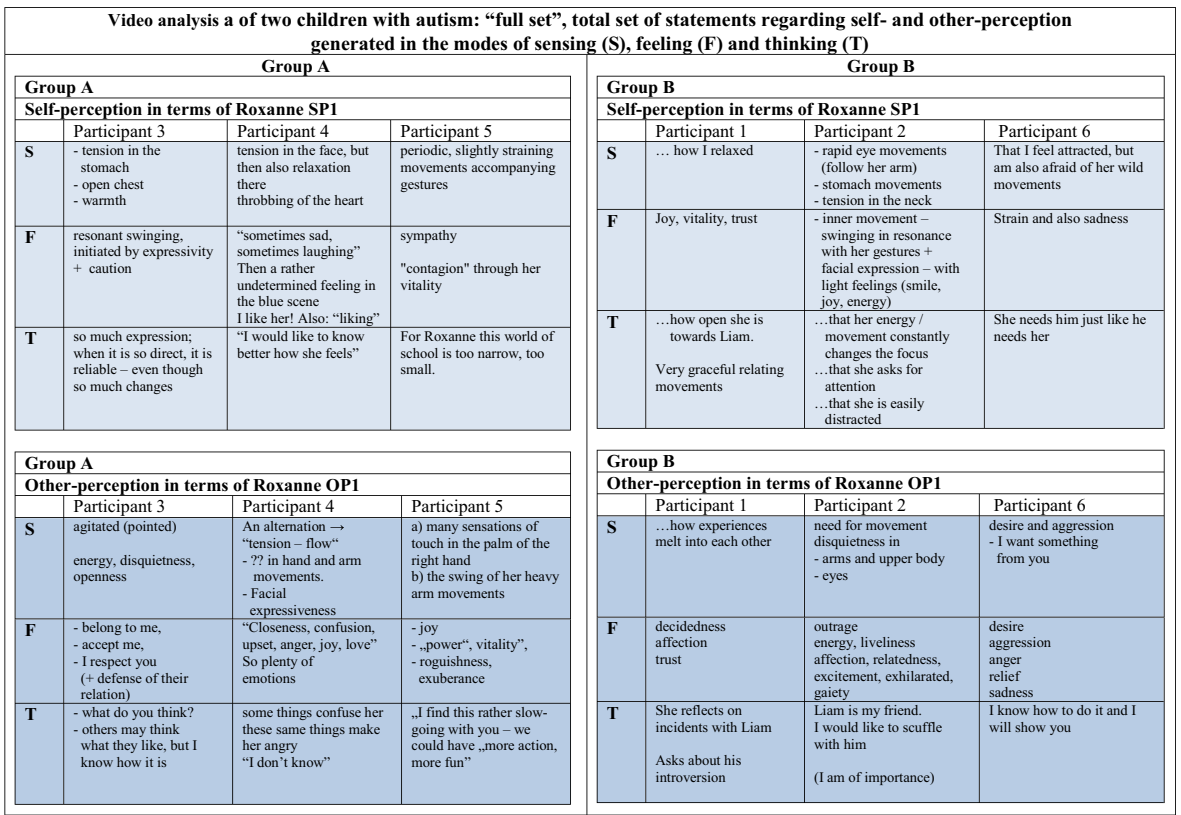


Table 3b Full set matrix regarding Liam. The notated approximations of all participants: self-perception and other-perception in terms of Liam, in the three modes: sensing, feeling, and thinking

\begin{tabular}{|c|c|c|c|c|c|c|c|}
\hline \multirow{2}{*}{\multicolumn{4}{|c|}{$\begin{array}{l}\text { Group A } \\
\text { Self-perception in terms of Liam SP2 }\end{array}$}} & \multicolumn{4}{|c|}{ Group B } \\
\hline & & & & \multicolumn{4}{|c|}{ Self-perception in terms of Liam SP2 } \\
\hline & Participant 3 & \begin{tabular}{|l|} 
Participant 4 \\
\end{tabular} & Participant 5 & & Participant 1 & Participant 2 & Participant 6 \\
\hline $\mathbf{S}$ & $\begin{array}{l}\text { relaxation } \\
\text { quietness + agitated } \\
\text { composed in myself }\end{array}$ & $\begin{array}{l}\text { jaw drop } \\
\text { somewhat rigid posture } \\
\text { in hands }\end{array}$ & $\begin{array}{l}\text { first strong tension in my } \\
\text { own face } \\
\text { then feelings of slowing } \\
\text { down } \\
\text { "Slow Motion" }\end{array}$ & $\mathbf{S}$ & $\begin{array}{l}\text { strained, tense in } \\
\text { shoulders and stomach }\end{array}$ & $\begin{array}{l}\text { - more consolidated in } \\
\text { sitting } \\
\text { - impulse to lift and } \\
\text { cross the arms } \\
\text { - impulse to cross the } \\
\text { left leg over the right } \\
\text { and to turn to the right }\end{array}$ & $\begin{array}{l}\text { insecurity and I felt } \\
\text { excluded }\end{array}$ \\
\hline $\mathbf{F}$ & inclination to shake him & $\begin{array}{l}\text { "I feel I want to protect } \\
\text { him, but at the same time } \\
\text { I also admire how well } \\
\text { he's doing } \\
\text { But still protectiveness }\end{array}$ & $\begin{array}{l}\text { worriedness, } \\
\text { need of protection }\end{array}$ & $\mathbf{F}$ & reluctance, worriedness & $\begin{array}{l}\text { - my own quickness } \\
\text { - need of protection } \\
\text { - more concentration } \\
\text { is needed for attention }\end{array}$ & $\begin{array}{l}\text { fear } \\
\text { and } \\
\text { compassion } \\
\text { and } \\
\text { emotion }\end{array}$ \\
\hline $\mathbf{T}$ & $\begin{array}{l}\text { - would he like her as } \\
\text { much as she likes } \\
\text { him? } \\
\text { - I would feel the } \\
\text { impulse to hit him- } \\
\text { seems as an easier } \\
\text { contact than } \\
\text { "caressing" }\end{array}$ & $\begin{array}{l}\text { "Aiai, I wish I would } \\
\text { fasten him a bit" }\end{array}$ & $\begin{array}{l}\text { The boy would need a } \\
\text { training in boxing }\end{array}$ & $\mathbf{T}$ & $\begin{array}{l}\text {...that he is rather } \\
\text { locked-in and } \\
\text { insecure } \\
\text {...that he doesn't want } \\
\text { anything from others }\end{array}$ & $\begin{array}{l}\text {...that contact for Liam } \\
\text { quickly gets too much } \\
\text { (as well as stimuli) } \\
\text {...that he has to make } \\
\text { a big effort to } \\
\text { perceive them }\end{array}$ & $\begin{array}{l}\text { Great, how many things } \\
\text { he already dares and does }\end{array}$ \\
\hline \multicolumn{4}{|c|}{ Group A } & \multicolumn{4}{|c|}{ Group B } \\
\hline \multicolumn{4}{|c|}{ Other-perception in terms of Liam OP2 } & \multicolumn{4}{|c|}{ Other-perception in terms of Liam OP2 } \\
\hline & Participant 3 & \begin{tabular}{|l|} 
Participant 4 \\
\end{tabular} & Participant 5 & & Participant 1 & Participant 2 & Participant 6 \\
\hline $\mathbf{S}$ & $\begin{array}{l}\text { attention (directed to the } \\
\text { outside) } \\
\text { passivity }\end{array}$ & $\begin{array}{l}\text { I am light, skinny and a } \\
\text { little bit stiff (?) }\end{array}$ & $\begin{array}{l}\text { a) be softly touched } \\
\text { several times } \\
\text { b) to touch oneself }\end{array}$ & $\mathbf{S}$ & $\begin{array}{l}\text { externally lumbering and } \\
\text { insecure everything is } \\
\text { asking too much } \\
\text { preference to internally } \\
\text { withdraw }\end{array}$ & $\begin{array}{l}\text { holding on to oneself or } \\
\text { objects } \\
\text { to retreat, to go back, to } \\
\text { move away } \\
\text { to hold off hands } \\
\text { physical contact }\end{array}$ & $\begin{array}{l}\text { I feel challenged and I } \\
\text { like it, but I don't always } \\
\text { know what she wants }\end{array}$ \\
\hline $\mathbf{F}$ & $\begin{array}{l}\text { what happens then? } \\
\text { be amusedly carried } \\
\text { along } \\
+ \text { so far and no further }\end{array}$ & $\begin{array}{l}\text { confusion, closeness } \\
\text { „I have to stand my } \\
\text { ground“", being pulled } \\
\text { and pushed, but often not } \\
\text { unwantingly so }\end{array}$ & $\begin{array}{l}\text { excessive demands } \\
\text { (I can't follow) } \\
\text { helplessness (what does } \\
\text { happen to me?) } \\
\text { absence } \\
\text { drifting off }\end{array}$ & $\mathbf{F}$ & $\begin{array}{l}\text { superficially threat, but } \\
\text { deep down the feeling of } \\
\text { security with Roxanne }\end{array}$ & $\begin{array}{l}\text { need of protection } \\
\text { effort to assimilate, to } \\
\text { concentrate, to } \\
\text { differentiate } \\
\text { curious } \\
\text { surprised }\end{array}$ & $\begin{array}{l}\text { confsion } \\
\text { curiosity } \\
\text { joy }\end{array}$ \\
\hline $\mathbf{T}$ & $\begin{array}{l}\text {...she only shouldn't let } \\
\text { me... }\end{array}$ & $\begin{array}{l}\text { I don't know } \\
\text { what should I do? } \\
\text { where are we going? } \\
\text { why does she do that? } \\
\text { Hey, not like that! }\end{array}$ & $\begin{array}{l}\text { I don't exactly know } \\
\text { what she actually wants } \\
\text { from me, but I'll try to } \\
\text { participate }\end{array}$ & $\mathbf{T}$ & $\begin{array}{l}\text { what do they all want } \\
\text { from me } \\
\text { interesting patterns on the } \\
\text { ceiling } \\
\text { Roxanne is okay }\end{array}$ & $\begin{array}{l}\ldots \text { that Roxanne is my } \\
\text { friend } \\
\ldots \text { that she talks very } \\
\text { fast } \\
\ldots \text { that the ceiling has } \\
\text { an interesting colour } \\
\ldots \text { that she shouldn't } \\
\text { beat me }\end{array}$ & $\begin{array}{l}\text { what???? } \\
\text { I want to find out! }\end{array}$ \\
\hline
\end{tabular}

Table 3c Full set matrix regarding the in-between. The notated approximations of all participants: selfperception and other-perception in terms of the in-between, in the three modes: sensing, feeling, and thinking

\begin{tabular}{|c|c|c|c|}
\hline \multicolumn{4}{|c|}{ Group A } \\
\hline \multicolumn{4}{|c|}{ Self-perception in terms of interaction between R\&L SP3 } \\
\hline & Participant 3 & Participant 4 & Participant 5 \\
\hline $\mathbf{S}$ & $\begin{array}{l}\text { openness } \\
\text { tension in the stomach }\end{array}$ & $\begin{array}{l}\text { I sensed my arms, hands } \\
\text { and shoulders, at the same } \\
\text { time light and heavy and } \\
\text { tight }\end{array}$ & $\begin{array}{l}\text { vulnerability given } \\
\text { intensive movements }\end{array}$ \\
\hline $\mathbf{F}$ & $\begin{array}{l}\text { wonderful to see it }+ \\
\text { a little bit of jealousy }\end{array}$ & $\begin{array}{l}\text { Love empathy, but a } \\
\text { certain tension. I'd like to } \\
\text { open my arms }\end{array}$ & $\begin{array}{l}\text { very mixed feelings given } \\
\text { intuitive movements }\end{array}$ \\
\hline $\mathbf{T}$ & $\begin{array}{l}\text { - her activity }+ \text { his } \\
\text { reactivity fit together } \\
\text { - does she inforce his } \\
\text { stability by respect for } \\
\text { him }\end{array}$ & $\begin{array}{l}\text { They don't know how } \\
\text { to do it. But some } \\
\text { things work } \\
\text { nevertheless }\end{array}$ & $\begin{array}{l}\text { an unequal couple, but } \\
\text { they like each other a } \\
\text { lot }\end{array}$ \\
\hline
\end{tabular}

\begin{tabular}{|c|c|c|c|}
\hline \multicolumn{4}{|c|}{ Self-perception in terms of interaction between R\&L SP3 } \\
\hline & Participant 1 & Participant 2 & Participant 6 \\
\hline $\mathbf{S}$ & $\begin{array}{l}\text { ambivalent feelings } \\
\text { disturbed flow, } \\
\text { somehow dissatisfying }\end{array}$ & $\begin{array}{l}\text { - arms press on the } \\
\text { backrest } \\
\text { - foot is twisted } \\
\text { - eyes move away from } \\
\text { the picture }\end{array}$ & $\begin{array}{l}\text { that I get touched } \\
\text { by them } \\
\text { I like this well-rehearsed } \\
\text { game } \\
\text { I enjoy it }\end{array}$ \\
\hline $\mathbf{F}$ & joy, affection & $\begin{array}{l}\text { changing } \\
\text { between curiosity (to } \\
\text { understand) and tiredness } \\
\text { (of repetition) } \\
\text { attention often } \\
\text { more with her }\end{array}$ & $\begin{array}{l}\text { warmth } \\
\text { freedom } \\
\text { curiosity }\end{array}$ \\
\hline $\mathbf{T}$ & $\begin{array}{l}\text { - that they deal a lot } \\
\text { with borders } \\
\text { - very good that Liam } \\
\text { has Roxanne } \\
\text { - somehow it is } \\
\text { beautiful to see }\end{array}$ & $\begin{array}{l}\text { - that R. dominates the } \\
\text { interaction, whereas } \\
\text { Liam reacts } \\
\text { - that both have a } \\
\text { conflict and solve it } \\
\text { - that they like each } \\
\text { other }\end{array}$ & $\begin{array}{l}\text { - that they are like an } \\
\text { old couple }\end{array}$ \\
\hline
\end{tabular}

\begin{tabular}{|c|c|c|c|}
\hline \multirow{2}{*}{\multicolumn{4}{|c|}{$\begin{array}{l}\text { Group A } \\
\text { Other-perception in terms of interaction between R\&L OP3 }\end{array}$}} \\
\hline & & of interaction betwe & R\&L OP3 \\
\hline 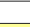 & Participant 3 & Participant 4 & Participant 5 \\
\hline $\mathbf{S}$ & relaxation + excitement & $\begin{array}{l}\text { closeness + distance } \\
\text { alternation } \\
\text { warm back at the end } \\
\text { "fluttering" }\end{array}$ & $\begin{array}{l}\text { to be linked together as a } \\
\text { very unequal couple, in } \\
\text { constant "polarity between } \\
\text { activity-passivity" (,Push } \\
\text { me - Pull you“) }\end{array}$ \\
\hline $\mathbf{F}$ & $\begin{array}{l}\text { security, respect, trust } \\
\text { R: desire for contact } \\
\text { + reassurance of contact }\end{array}$ & $\begin{array}{l}\text { In their togetherness the } \\
\text { weight is heavier on one } \\
\text { side }\end{array}$ & $\begin{array}{l}\text { still feeling very related to } \\
\text { each other, even needing } \\
\text { each other (in all } \\
\text { differentness) }\end{array}$ \\
\hline $\mathbf{T}$ & We are friends & $\begin{array}{l}\text { We don't know how to } \\
\text { do this. We try things, } \\
\text { sometimes they work, } \\
\text { sometimes they don't" }\end{array}$ & $\begin{array}{l}\text { "Somehow we belong } \\
\text { together, here we are } \\
\text { something special“" }\end{array}$ \\
\hline
\end{tabular}

\begin{tabular}{|c|c|c|c|}
\hline \multicolumn{4}{|c|}{ Group B } \\
\hline \multicolumn{4}{|c|}{ Other-perception in terms of interaction between R\&L OP3 } \\
\hline & Participant 1 & Participant 2 & Participant 6 \\
\hline $\mathbf{S}$ & $\begin{array}{l}\text { oscillating between } \\
\text { closeness and distance }\end{array}$ & $\begin{array}{l}\text { taking space (her) } \\
\text { tightening space (him) } \\
\text { looking for physical } \\
\text { contact and holding it off }\end{array}$ & $\begin{array}{l}\text {...having fun with each } \\
\text { other, liking to challenge } \\
\text { each other } \\
\text { "What would I be } \\
\text { without you?" }\end{array}$ \\
\hline $\mathbf{F}$ & $\begin{array}{l}\text { to be familiar, to feel } \\
\text { accepted }\end{array}$ & $\begin{array}{l}\text {...constant change } \\
\text { between ,succeeding", } \\
\text { "rather harmonic" } \\
\text { contact and lacking } \\
\text { congruity } \\
\text { alternating between } \\
\text { affection and "missing } \\
\text { each other" }\end{array}$ & $\begin{array}{l}\ldots \text { to like each other and } \\
\text { being happy to have each } \\
\text { other }\end{array}$ \\
\hline $\mathbf{T}$ & ? & $\begin{array}{l}\text { liking each other } \\
\text { criticizing each other } \\
\text { wanting to be friends } \\
\text { wanting to be oneself }\end{array}$ & $\begin{array}{l}\text { knowing how they } \\
\text { benefit from each other }\end{array}$ \\
\hline
\end{tabular}


Roxanne and Liam each play quite different parts, e.g. "power, vitality" (3a, P5, OP, F, regarding Roxanne $)^{8}$ versus "helplessness, absence, drifting off” (3b, OP2, P5, F, regarding Liam). This is reflected in the in-between in terms of a certain tension, e.g.: "still feeling very related to each other, (even needing each other in all differentness)" (3c, P5, OP, F); "... constant change between 'succeeding', 'rather harmonic' contact and lacking congruity/alternating between affection and "missing each other"' (3c, P2, OP, F); "liking each other/ criticizing each other/wanting to be friends/wanting to be oneself" (3c, P2, OP, $\mathrm{T}$ ); "to be linked together as a very unequal couple, in constant "polarity between activity-passivity' ('Push me - Pull you')" (3c, P5, OP, S).

Participants' initial approximations (Table 2, e.g. "Two young people, who seem to be friends, in several interaction situations, with an idiosyncratic, ambivalent-seeming exchange of gestures", P5) become refracted into several of its aspects, in quite precise terms that often recur in the notations of several participants. For instance, the "ambivalent-seeming exchange of gestures" is appreciated in "joy," "vitality," "tension," oscillation, polarity, alternation (notations recurring in several places in Table 3a, regarding Roxanne, and 3c, regarding the in-between), versus "need of protection" (emerging in several notations in Table 3b, regarding Liam). Another example is the contrast between "we could have "more action, more fun"" (3a, P5, OP, T, regarding Roxanne) and "The boy would need a training in boxing" (3b, P5, SP, T, regarding Liam). The children "seem to be friends" (3c, P5, SP, T), and "an unequal couple, but they like each other a lot" (3c, P5, SP, T).

After the full set was completed, the participants performed one final viewing. This final approximation was generated by applying a conFiguration process (explained in section 3): After selecting a particular notation from the full set of statements, each participant produced additionally and on purpose this chosen sensation, feeling, or thought, while once again viewing the video and taking a particular perceptual reference on it, as instructed by a prompt (given in Table 5). The selected statements came from the notations regarding participants' self-perceptions (SP) of what happened between Roxanne and Liam (Table 3c). Group A chose the statement "Love, empathy, but also a certain tension, I'd like to open my arms" (from SP-F, participant 4, Group A, Table 3c). Group B chose "an unequal couple, but they like each other a lot" (see participant 5, SP-T, Table 3c). The final notations that this resulted in are presented in Table 4.

Comparing the initial approximations in Table 2 and the final approximations in Table 4, and the full matrix (Tables $3 a, b$ and c), we can see that participants notice more and more specified aspects of the interaction, which remained undetected or hidden at first. One striking result regards Liam: In the first approximations, it is already noticed that the two children behave and move very differently: one "wilder, more demanding" and "gently, rather careful" (see Table 2). In the full set, it was noticed that Liam is "doing well" in various places, as well as that there are tensions in his demeanour, e.g. "I feel challenged and I like it, but don't always know what she wants"

\footnotetext{
${ }^{8}$ Guide to where to find the notations in the tables: With each quote, we give table number (3a), participant number (P5), reference of perception (self-perception: SP, or other-perception: OP), and finally mode (sensing: $\mathrm{S}$, feeling: $\mathrm{F}$, or thinking: $\mathrm{T})$.
} 
Table 4 The final approximations, per group

\begin{tabular}{|c|c|c|c|}
\hline Group A & Participant 4 & Participant 3 & Participant 5 \\
\hline $\begin{array}{l}\text { Wording of the } \\
\text { final prompts: }\end{array}$ & $\begin{array}{l}\text { While producing the selected } \\
\text { statement additionally and on } \\
\text { purpose I put myself in } \\
\text { Roxanne's shoes. It seemed to } \\
\text { me that she..... }\end{array}$ & $\begin{array}{l}\text { While producing the selected } \\
\text { statement additionally and on } \\
\text { purpose I put myself in Liam's } \\
\text { shoes. It seemed to me that } \\
\text { he..... }\end{array}$ & $\begin{array}{l}\text { While producing the selected } \\
\text { statement additionally and on } \\
\text { purpose I put myself in the } \\
\text { interaction between Roxanne } \\
\text { and Liam. It seemed to me that } \\
\text { the two of them }\end{array}$ \\
\hline $\begin{array}{l}\text { ConFigured } \\
\text { statement: } \\
\text { "Love, empathy, } \\
\text { but also a certain } \\
\text { tension, I'd like to } \\
\text { open my arms" }\end{array}$ & & & \\
\hline Approximations: & $\begin{array}{l}\text { "...smiled (more than I saw } \\
\text { before) but at a certain point the } \\
\text { smiling was also completely } \\
\text { absent. Then it erupted again } \\
\text { and then it went back and forth } \\
\text { between smiling and angry } \\
\text { face" }\end{array}$ & $\begin{array}{l}\text { "... manages, in his own way, to } \\
\text { stay in contact with her and with } \\
\text { himself" }\end{array}$ & $\begin{array}{l}\text { "...showed even more } \\
\text { something like a "shared } \\
\text { dance", a playing-together" }\end{array}$ \\
\hline
\end{tabular}

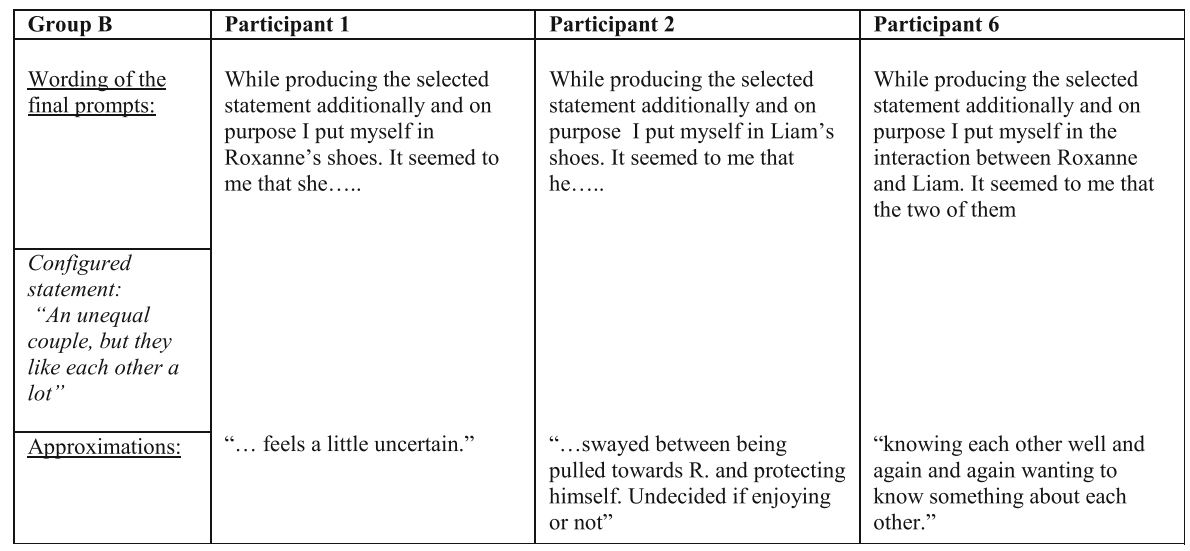

(3b, P6, OP, S), and "superficially threat, but deep down the feeling of security with Roxanne" (3b, P1, OP, F). But it is only in the final approximation that a participant (no. 3) notes down "he manages, in his own way, to stay in contact with her and with himself" (Table 4, P3). This relational quality of Liam's behaviour - remaining in touch with himself and Roxanne - had not yet been detected in the initial approximation (Table 2), nor fully in the full set (Table 3b).

In the final plenary discussion at the end of the experiment, the participants wondered Why are these children diagnosed with autism? This question was considered by the group to sum up the end-result or outcome of the workshop. While the children may have seemed strange in their interactions (in accordance with the diagnostic criteria for autism), at the same time the researcherparticipants attuned themselves to many intricately social things that the 
children were doing. ${ }^{9}$ They uncovered fine-grained aspects of their embodied interaction, confirming research which suggests that children with autism do have certain capacities for interactionally coordinating, when the behaviours are studied within their interactional context (cf. Stribling et al. 2005-06, 2007; Dickerson et al. 2007; Sterponi and Shankey 2014). ${ }^{10}$ In PRISMA, this is met by systematically considering - in its concepts and its empirical investigations - the interactors as well as the in-between, all of them integral components of the interaction.

The prismatic investigation reveals that a potentially subtle embodied instrument for understanding autism consists in a group of researchers engaging in a sustained, systematic, intersubjective unfolding of interactive experience. If it is true that the different ways in which people with autism move, both individually and with others, affect their ways of understanding the world and of thinking (as suggested by Hobson 2002; Donnellan et al. 2013; De Jaegher 2013), then PRISMA offers a tool for testing and refining this claim.

\subsection{Thinking and interacting}

The second experiment was conducted as a one-day workshop at the University of the Basque Country, San Sebastián, in October 2013. Six participants took part, four females and two males, between twenty-five and sixty-five years old. Five were academics (two of them also Feldenkrais practicioners), working in psychology, sociology, cognitive science, and philosophy, and one city council administrator.

In the experiment presented in 4.1, self-perception, other-perception and the in-between were addressed as equal references for perceiving the interaction. In this workshop, we focused directly on the in-between, an aspect of which is intercorporeality. Intercorporeality is a mutual embodiment of intentions, which Merleau-Ponty understands as being "achieved through the reciprocity between my intentions and the other person's gestures, and between my gestures and the intentions which can be read in the other person's behavior" (Merleau-Ponty 1945/2012, p. 190-191). We hypothesised that

\footnotetext{
${ }^{9}$ In another, later workshop that we did on this same video (but with a different protocol), we found similar results (workshop San Sebastián, May 2012, 18 participants, one-day workshop). For instance, participant 10: initial approximation: "Two people, friends, perhaps had had trouble. Girl very expressive, boy difficulty expressing, concentration, seems to be "in his world" - final approximation: "They are together to defend their relationship from others, others are threatening". Participant 12: Initial approximation: "girl was very engaging, boy seemed a bit in his own world, separated from her, she tries to involve him, he feels overwhelmed by her, they have a fight" - final approximation: "She was the narrative/s. He was the adjective/s, but they were the overall story“. Participant 15: initial approximation: "two young people, first interacting, then both being interviewed in front of the camera" - final approximation: "There are two poles to everything". Here again, we see an increasingly nuanced appreciation of what goes on in the video between the initial and the final approximation.

${ }^{10}$ An interesting reverse argument is that the ways in which people with autism depart from the norms of communication and social interaction may in fact reflect prevalent elements of intersubjectivity that contribute to the general (mis-)communication in everyday interactions, see Sterponi and Fasulo (2010).
} 
intercorporeality is a part of social interaction, and more than the sum of each interactor's activities. Its investigation in this experiment should therefore not focus on single agents' doings, nor on a particular pre-established interactive situation. The title of the workshop was "Grasping the experience of interacting: How can the experience of interacting and intercorporeality be investigated bodily?" We invited the participants to study this question by engaging in brief contact improvisations. Contact improvisation is a contemporary dance style developed in the early 1970's in the USA, and first named as such in 1972 by Steve Paxton (Novack 1990). Novack describes how "The dancers in contact improvisation focus on the physical sensations of touching, leaning, supporting, counterbalancing, and falling with other people, thus carrying on a physical dialogue" (p. 8). This heightening of embodied aspects of interactive experience, which can, in some sense, be considered analogous to the experience of less clearly embodied interactions, makes it well suited for a PRISMA investigation.

Different from the first experiment, where the investigation was of a video, in this workshop the researchers engaged in live interactions. Other live interaction workshops we have done usually involved a particular kind of short interaction (e.g. helping someone into their coat). In this workshop, because it was based on improvisation (an element also generally present in daily life interactions), each subsequent interaction engaged in during the day was novel, rather than a 'repetition' of a particular interaction. Since we were looking for principles of intercorporeality's role in intersubjectivity, it should not matter which precise interaction the participants engage in; any kind of interaction should show us something about that role.

We approached the question about intercorporeality head-on, in that we formulated all prompts in terms of the 'in-between,' as can be seen in Tables 5 and 6. The participants worked in two groups of three: two interactors and one observer. Each participant did a self-perception and an other-perception regarding the in-between in only one role (interactor or observer), initially generating matrices of 6 findings. The most exciting results in this experiment, however, were generated in the conFiguration processes after the initial matrices were filled.

After the groups each gathered a full matrix, each group searched for a similarity out of their approximations, and conFigured it in order to generate a refinement. After this, the matrices were exchanged between groups, so that group A inspected group B's matrix, and vice versa. Now, each group searched for a similarity in the 'foreign' matrix for conFiguring and refining. Here, we present two of these conFiguration and exchange processes.

First, we present the data from the initial matrix, generated in the mode of thinking by group A (Table 5).

When group A searched for similarities in their matrix (Table 5), they noted two similarities: "connection emerged" and "not much thinking". They selected the latter as 'interim-finding' for further processing. After producing this on purpose by doing "not much thinking" during a further contact improvisation, participants refined it as "Three aspects of thinking: commentary, controlling, judgement. There are ways of thinking that are not 
Table 5 Matrix showing prompts and participants' approximations of the experience of interacting. Self- and Other-perception regarding the in-between; two interactors, one observer, Group A, in the mode of thinking

\begin{tabular}{|c|c|c|}
\hline \multirow{2}{*}{$\begin{array}{l}\text { Group A } \\
\text { Thinking }\end{array}$} & \multicolumn{2}{|c|}{ Perceptions regarding what happened between interactors } \\
\hline & $\begin{array}{l}\text { a) Self-perception (SP) } \\
\text { Thinking }\end{array}$ & $\begin{array}{l}\text { b) Other-perception (OP) } \\
\text { Thinking }\end{array}$ \\
\hline 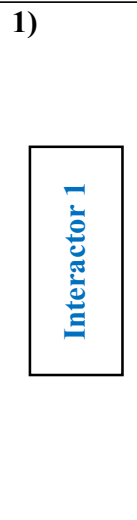 & $\begin{array}{l}\text { 1a) SP T - I } 1 \\
\text { During the practice sequence I perceived } \\
\text { what happened between the two } \\
\text { interactors } \\
\text { and thought to myself... } \\
\text {...that we had to find out a common } \\
\text { way of sharing this experience: it } \\
\text { conducted us from a progressive } \\
\text { approach to near contact without } \\
\text { looking at each other, and ended } \\
\text { with a dance that allowed eye } \\
\text { contact and taking a distance in } \\
\text { complicity. }\end{array}$ & $\begin{array}{l}\text { 1b) OP T - I } 1 \\
\text { During the practice sequence I put myself } \\
\text { in what happened between the two } \\
\text { interactors. } \\
\text { With regard to thinking, it seemed to me } \\
\text { that between them.... } \\
\text {...there was a "running after" "who } \\
\text { are you and who am I" with respect } \\
\text { to each another: a questioning of } \\
\text { mutual relationship and readiness to } \\
\text { go for different qualities of it: where } \\
\text { can I conduct you, will you follow } \\
\text { me, and what do you suggest to me? }\end{array}$ \\
\hline 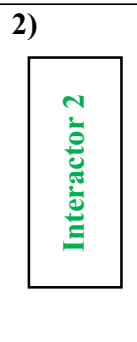 & $\begin{array}{l}\text { 2a) SP T - I } 2 \\
\text { During the practice sequence I perceived } \\
\text { what happened between the two } \\
\text { interactors } \\
\text { and thought to myself... }\end{array}$ & $\begin{array}{l}\text { 2b) OP T - I } 2 \\
\text { During the practice sequence I put myself } \\
\text { in what happened between the two } \\
\text { interactors. } \\
\text { With regard to thinking, it seemed to me } \\
\text { that between them.... } \\
\text {...some connection emerged as the } \\
\text { movements developed. Maybe due to } \\
\text { less thinking. }\end{array}$ \\
\hline $\begin{array}{l}\vdots \\
\vdots \\
0 \\
0 \\
0\end{array}$ & $\begin{array}{l}\text { 3a) SP } \mathrm{T}-\mathrm{O} \\
\text { During the practice sequence I perceived } \\
\text { what happened between the two } \\
\text { interactors } \\
\text { and thought to myself... }\end{array}$ & $\begin{array}{l}\text { 3b) } \mathrm{OP} \mathrm{T}-\mathrm{O} \\
\text { During the practice sequence I put myself } \\
\text { in what happened between the two } \\
\text { interactors. } \\
\text { With regard to thinking, it seemed to me } \\
\text { that between them.... } \\
\text {...there wasn't so much thinking, } \\
\text { more movement. Or, a difference in } \\
\text { thinking. }\end{array}$ \\
\hline
\end{tabular}

(C) Daniel Clénin und Barbara Pieper, PRISMA Projects, Munich/Berne 2015

controlling or judging. T-shirt message: less control and judgement, more commentary". 11

When group B scrutinised this same matrix (group A's) for similarities, they also found two, and formulated them as follows: "The connection was progressive through the interaction" and "Thinking was not a priority, but probably an obstacle to the

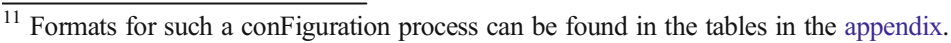


interaction". Group B chose the latter for conFiguring. After producing this on purpose in a new short contact improvisation, group B formulated the refinement: "The task of not bringing thinking into priority goes together with a relief, and this enables even obstacles to become part of the in-between".

It is worth noticing that both groups independently detected "connection" and "thinking" as similarities in group A's matrix, and both came up with quite specific refinements in the addressed thinking aspects, and in revealing coherencies - contributing to a fuller picture of group A's recorded interaction. Such results in comparing material among groups are characteristic for how the PRISMA procedures allow to reach 'graspable' findings. Moreover, the participants involved in this process grow more and more confident of their perceptual capacities as they realize the reliability of the findings.

The groups also gathered data in the modes of feeling (group A) and sensing (group B). Each group practised contact improvisation in just one of these modes. Here we take a closer look at group A's matrix (Table 6), and both groups' conFigurations of it.

Group A detected and formulated out of their own matrix (Table 6) the similarity "surprise-uncertainty". After conFiguring "surprise-uncertainty" in the mode of feeling in another contact improvisation, they refined it as follows: "Allowing for uncertainty leads to even more trust". When group B looked over this same matrix from group A, they formulated the similarity "At the start, when interaction seems blocked, there are tension asymmetries and clumsiness". Group B now, while producing "tension asymmetries and clumsiness," used the mode of sensing (previously applied in their own process), and refined the conFigured similarity into "The bodily tension (forces, support, pulling, pushing) could be used to unblock the flow of interaction". Methodologically, this shift in the mode of experiencing the interaction, from feeling to sensing, allowed different aspects to emerge than those found at first. Moreover, the embodied engagement in the interaction process revealed that the bodily aspects of interacting could be used to unblock tensions.

Together, these findings confirm something we all know well: that thinking can be an obstacle to interacting and that, with less thinking, interactions can be more fluid. But it also significantly refines this common insight, and supports embodied theories of intersubjectivity in their emphasis on the roles of interacting and embodiment. The individual activity of thinking may interrupt the flow or temporary autonomy of an interaction process (De Jaegher and Di Paolo 2007; De Jaegher et al. 2010). Furthermore, it seems that, when allowing for uncertainty in the interaction, there is more trust. And when there is tension, focusing on its bodily aspects ("forces, support, pulling, pushing") and away from thinking, can help loosen or even unblock unease in the flow of interaction. This confirms the centrality of interaction's role in intersubjectivity, and moreover, that it is possible to investigate this in bodily and experiential ways, which can generate novel insights. The findings we present here are in line with research supporting the use of body therapies in the treatment of various psychiatric disorders, for instance schizophrenia and autism (Behrends et al. 2012; Galbusera and Fuchs 2014; Maiese 2016; Martin et al. 2016). PRISMA can be used to help further refine ways to test and improve such ideas. 
Table 6 Matrix showing the prompts and participants' approximations of the experience of interacting. Selfand Other-perception regarding the in-between; two interactors, one observer, group A, in the mode of feeling (the question mark in brackets represents a word that was unreadable at the stage of transcription)

\begin{tabular}{|c|c|c|}
\hline \multirow{2}{*}{$\begin{array}{l}\text { Group A } \\
\text { Feeling }\end{array}$} & \multicolumn{2}{|c|}{ Perceptions regarding what happened between Interactors } \\
\hline & $\begin{array}{l}\text { a) Self-perception (SP) } \\
\text { Feeling }\end{array}$ & $\begin{array}{l}\text { b) Other-perception (OP) } \\
\text { Feeling }\end{array}$ \\
\hline 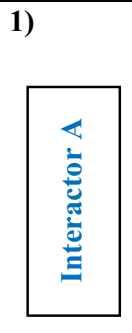 & $\begin{array}{l}\text { 1a) SP F - I } 1 \\
\text { During the practice sequence I perceived } \\
\text { what happened between the two } \\
\text { interactors and felt in myself... } \\
\text { Warmth, roundness, clumsiness, } \\
\text { laughter, expectation, curiosity, } \\
\text { constrained freedom. }\end{array}$ & $\begin{array}{l}\text { 1b) OP F - I } 1 \\
\text { During the practice sequence I put myself } \\
\text { in what happened between the two } \\
\text { interactors. } \\
\text { With regard to feeling, it seemed to me } \\
\text { that between them.... } \\
\text { There was contact, expectation, some } \\
\text { (?), "being able", "can I?" }\end{array}$ \\
\hline 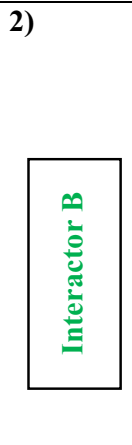 & $\begin{array}{l}\text { 2a) SP F - I } 2 \\
\text { During the practice sequence I perceived } \\
\text { what happened between the two } \\
\text { interactors and felt in myself... } \\
\text {..that my partner was a bit uncertain } \\
\text { in the beginning, so time was needed } \\
\text { to get more confident with the } \\
\text { situation; and as it got, then dancing } \\
\text { together was pleasant, surprising and } \\
\text { no more anxiety. }\end{array}$ & $\begin{array}{l}\text { 2b) OP F - I } 2 \\
\text { During the practice sequence I put myself } \\
\text { in what happened between the two } \\
\text { interactors. } \\
\text { With regard to feeling, it seemed to me } \\
\text { that between them.... } \\
\text {..there was asymmetry in the } \\
\text { beginning, which then evolved to a } \\
\text { more symmetrical sharing of playing } \\
\text { with movement, daring try out and } \\
\text { accept surprising situations with } \\
\text { pleasure. }\end{array}$ \\
\hline $\begin{array}{l}\vdots \\
\vdots \\
0 \\
0 \\
0\end{array}$ & $\begin{array}{l}\text { 3a) SP } \mathrm{F}-\mathrm{O} \\
\text { During the practice sequence I perceived } \\
\text { what happened between the two } \\
\text { interactors and felt in myself... } \\
\text { Peaceful. Tense on occasions as a } \\
\text { new direction unfolded uncertainly, } \\
\text { then felt admiration as the } \\
\text { interaction emerged again. }\end{array}$ & $\begin{array}{l}\text { 3b) } \mathrm{OP} \mathrm{F}-\mathrm{O} \\
\text { During the practice sequence I put myself } \\
\text { in what happened between the two } \\
\text { interactors. } \\
\text { With regard to feeling, it seemed to me } \\
\text { that between them.... } \\
\text { There was gentleness, a sense of trust } \\
\text { that they can move together. Some } \\
\text { joy and peace on occasions as things } \\
\text { "clicked". }\end{array}$ \\
\hline
\end{tabular}

(C) Daniel Clénin und Barbara Pieper, PRISMA Projects, Munich/Berne 2015

\section{Discussion}

It is time for some reflections on the methods and empirical studies we have presented.

The whole PRISMA process could be described as a systematic unfolding of what normally is a unitary experience: understanding each other. This experience may be 
described as a 'mediated immediacy': our own bodily sensations serve as a tacit medium of interaffectivity, in which we directly perceive and intuitively understand another's expressions or intentions-in-action. In other words, the lived body functions as a "resonance board" of intercorporeality and interaffectivity (Polanyi 1967, Fuchs 2015). Moreover, even the emotions that we feel towards another person are often not in the focus of awareness but only marginally conscious. Instead, we are mostly directed towards the contents of our verbal communication, shared goals, joint practices, etc. PRISMA methodically dissolves this mediated immediacy. It directs our awareness to bodily sensations, feelings, and thoughts: What is normally passed over without awareness now becomes the focus of attention. In this way, the global, intuitive, but rather undifferentiated impression that we usually receive of another person and the shared situation is unfolded or refracted into its aspects, and in this way our perception is enriched in awareness, differentiation, and sensitivity. A PRISMA process shifts our attention from the goal or intentional content of the interaction to the process itself, in particular to the mediating aspects of perceiving oneself, the other, and the 'in-between'. The effect of the procedure may be compared to listening to a symphonic orchestra which conveys a holistic musical impression. When attending a rehearsal, however, it may happen that the director summons each instrument to play its part separately which we then hear without interference. Now when the tutti starts again, our listening experience will be much richer in detail, differentiation and concordance - enriched by the unraveling we have experienced in the interval.

Central to PRISMA's methodology is the repeated shifting of perspectives in the process. What this method and the findings it gives rise to offers, is a sophisticated 'kaleidoscopic' perspective on the interaction process. It furthers the investigation of participatory sensemaking's claim that interaction processes as such contribute to intersubjectivity.

An intriguing step in that direction concerns the significance of the in-between in interactions. PRISMA started in 2001 with the (self- and other-related) components of face-to-face perceptions of two interactors and an observer. The in-between only turned up much later, in video-format investigations. Allowing more distance to the object of investigation than face-to-face interactions, the participants were inclined to pick up our offer to sense themselves while focusing on what happens between the recorded interactors (Pieper and Clénin 2012); or even to put themselves, as it were, in the shoes of what happens between the two interactors. By then it became evident that the in-between could be regarded as a dynamic of its own within the interaction. These insights, empirically borne out also in our studies on the autistic children (section 4.1), could not have been made by concentrating just on the interactors' and the observer's self- and other-perception. Curious about this, we looked for analogue coherencies in face-to-face interactions by unfolding a process now designed to study the "interaction as such" (4.2).

Meanwhile we are on the verge of bringing it all together. We can now compose the interactors' and observer's self- and other-perception during the interaction regarding (1) themselves, (2) the others and (3) the in-between, analoguous to the video-format, but now in a live interaction of 3 to 4 participants. We aim to challenge our basic hypothesis on synchronicities in interaction as a socially constituted principle (sections 3.1 and 3.2) and its assumption that interactors and the in-between have equal weight and are inherently interlinked with each other. This hypothesis nicely matches theories and concepts like participatory sense-making and intercorporality. We expect growing insights into the subjective experience of interacting. In combination with empirical 
research on different aspects of interaction processes, this can lead to novel hypotheses, for example regarding intra- and interindividual coordination (Trevarthen and Aitken 2001; Laroche et al. 2014; Noy et al. 2015; Bachrach et al. 2015; Dumas et al. 2014; De Jaegher et al. 2016).

The findings presented can open doors to new investigations. The results of the first experiment (section 4.1) refine some ideas about autistic children's hampered capacities for interacting: While autism comes with certain social interactional problems, it seems that these do not necessarily prevent children with autism from having intricate reciprocal relationships, with certain specific characteristics. A further possibility would be to compare the PRISMA findings on the video-material of the children with autism with other kinds of qualitative research, such as conversation analysis, or quantitative measures of their interactional coordination. ${ }^{12}$

\section{Conclusion}

By introducing the PRISMA method, we hope to bring the "detached scientist" and the "ordinary person" of Vasu Reddy's epigram a little closer together when it comes to understanding how we experience and understand each other and the world together (intersubjectivity). After all, 'ordinary persons' (including the ordinary persons that academic researchers also are) are experts on intersubjectivity - if only because of their daily participation in it. The method we have introduced here is reproducible. The approach is systematic and documented: the data are available for other researchers to inspect, and manuals allow others to apply the method. They do not have to be scientists - the method spans disciplines and sectors. Intersubjectivity is an area in which lay-persons and scientists may have a lot to learn from each other, and it is one of the concerns of enactivism as a science of mind to bring subjectivity and intersubjectivity in the centre, and to investigate them as such, rectifying as much as possible their eradication from much of the sciences of the mind (a repeatedly registered dissatisfaction, see for instance Gurwitsch 1979, Bruner 1990, Reddy 2008).

What we have presented is a method to investigate experience as it transforms. This is why a PRISMA session is a workshop as well as an experiment. We expect and acknowledge that participants change during a session, and we make it explicit that a PRISMA workshop offers — besides an opportunity for an empirical investigation also a place to learn about interacting and its transformative experience. Participating in a PRISMA workshop is likely to increase and refine one's interactive experience, and thus have consequences for the researcher not just as researcher, but also as a person. This is in line with other deeply embodied approaches, for instance the work of Richard Shusterman, who affirms that studying the lived body can have meliorative consequences (Shusterman 2008). This is unavoidable given the nature of experience.

Individuals engaging in social encounters come with histories, perspectives, moods, affiliations, and so on. They are never neutral when they engage in interactions and

\footnotetext{
${ }^{12}$ In fact, we have initiated such a comparison. We have asked Fabian Ramseyer to do a Motion Energy Analysis (MEA, Ramseyer and Tschacher 2008) on the Roxanne and Liam video (section 4.1). He did an initial test, and found good synchrony between the two children, confirming our findings that the children seemed quite adept at certain aspects of interacting. This could be the starting point for a further study.
} 
participate in each other's sense-making. Meanings span individuals, and are often created and transformed in interactions. Cuffari, following Gendlin (1962/1997), conceives of meanings in terms of their "consequences for experience" (Johnson 2007, p. 10 ), or as "series of changes or implications in phenomenologically available felt sense and action possibilities" (Cuffari 2014, p. 4). Cuffari connects to this an ethics of interaction, a need to acknowledge the intricacies of interacting and to learn from our evaluations of them. "Immanent, embodied dimensions of our interactions — personal experience, social position, habituated reactions, emotional and physical vulnerabilities, and temporality," she says, "are our sources of caring and evaluating" (2014, p. 4). She also asks who will be our teacher, our guide, in these embodied interactions and their evaluations. This question is especially important when basic research questions also touch on normative questions about doing this kind of research. The answer refers back to us: We, the animated living beings, are the guides and teachers. We can do so in systematic, reproducible procedures that make us aware of sensing, feeling, and thinking while doing research together. PRISMA provides a way to access, structure, investigate, and better understand experience as it transforms (us) in interactions, as well as how engaged researchers (academics and others) use their transforming and transformative capacities for the sake of achieving deeper knowledge. After years of designing, experiencing, testing, and elaborating, we are confident that the practicaltheoretical prismatic approach can contribute to an enactive, ethical way of investigating subjectivity and intersubjectivity.

Acknowledgments We thank Ezequiel Di Paolo, Sanneke de Haan, Beata Stawarska, Elena Cuffari, and Melisa Stevanovic for comments on the manuscript, Heribert Sattel for logistic support, our workshop participants, everyone we have had helpful discussions with over the years, and two anonymous reviewers. The project received funding from Marie Curie RTN "DISCOS" (MC-RTN-2006-035975); Marie-Curie ITN "TESIS" (FP7-PEOPLE-2010-ITN, 264828); and, to HDJ: Marie Curie IEF “INDYNAUTS" (FP7-PEOPLE2009-IEF-253883), and Ramón y Cajal Fellowship RYC-2013-14583.

\section{Appendix}

\section{Practising PRISMA: An invitation to try out the method $^{13}$}

All you need is two willing colleagues (apart from yourself), some space to move around in, and a pen and paper for each participant. The experiment concerns a real time face-to-face interaction. The tasks are for two interactors and one observer. The interaction to be explored is about two people walking together (for no more than 2 minutes), plus one observer. The tasks (performed in silence) are: Interactor 1, walking forward, will guide interactor 2, who walks backwards. Interactor 1 can bring her hand on interactor 2's shoulder or arm for providing guidance. Interactor 1 is responsible for the partner's security. The observer locates himself at a certain distance. His task is to pay attention to what happens between the two interactors walking

\footnotetext{
13 This example was experienced in the context of investigating trust-building during a workshop with scientists in Munich («Trust and implicit knowledge - connected via embodied communication«, Institut für Sozialwissenschaftliche Forschung e.V., Munich, July 9 \& 10, 2012, see Pieper (2012)). Regarding trustbuilding in the context of an embodied approach, see Böhle et al. (2014).
} 
together. For your comfort, remove obstacles before starting. Don't talk during the interaction. Before starting, prepare two small pieces of paper and a pen per person. You will undertake two different approximations during the experiment.

\section{First Round: Self-perception}

While walking (both interactor 1 and 2) or while being the observer, your perception is at first mainly directed towards yourself. Each of you will focus on your own sensations while performing your particular task: Focus on your own response of sensing. ${ }^{14}$ Stay with sensing yourself while walking forward or backwards or while paying attention to what happens between the two walkers. Stay with those sensations that emerge regarding yourself while performing your part in the interaction - sensations like heart beat or leaning forward or stumbling or starting to smile or ... Leave aside feelings and thoughts that might come up, too. Don't worry about getting it right (there is no right or wrong), or about being able to capture everything (you won't be able to in any case). Just focus on sensing yourself during your task. Following only perceptions of sensing may be artificial at first. However it will later allow instructive comparisons. Stop after at most 2 minutes.

\section{Second Round: Other-perception}

Continue with the task of walking in a pair, plus an observer, in the same roles. But now, being interactor 1, put yourself in interactor 2's place ("put yourself in her shoes") while guiding her backwards. Estimate what she might sense. Similarly for interactor 2: Put yourself in the shoes of interactor 1, who is walking forward. What might interactor 1 sense? And as observer, put yourself in what happens between the two. Sense what seemed to you to happen with respect to the walkers' in-between. Direct yourself towards the other's presumed sensory perceptions. Try to sense like the other interactor might have sensed herself; or (for the observer) try to sense what might happen between the two.

\section{Third Round: Notation and Sharing}

Immediately after finishing, write down your impressions as they come up - first your own self-perception, and then your other-perception while putting yourself in your partner's shoes or, for the observer, regarding the in-between of the pair. For recording, you could use the prompts of Table 1 (section 3.1). ${ }^{15}$ Compile your notations: first place the self- and other-perception of interactor 1 , one next to the other. Then below this, interactors 2's self- and other-perception, one next to the other. In a third row, place the oberver's two statements. In this way, systematically order all 6 statements. This forms the matrix (introduced in section 3.1 and formalized in Table 1). Share and compare the findings. Maybe you find similarities in how the three of you perceived this same interaction? Do your notations on self- and other-perception differ? If yes: how? And what about sensing? Maybe the recorded experiences are closer to feeling or even to

\footnotetext{
${ }^{14}$ In the experiment as described here, the approximations take place in terms of sensing. Of course, you can also do it in terms of feeling or of thinking, or add rounds for each of these, if you wish.

${ }^{15}$ By employing the identical set of prompts for all participants you ensure the same preconditions in the prompts' language and equivalence of roles.
} 
thinking than to sensing? Never mind: Change roles and start again, or remain in your roles, but now use the mode of feeling while experiencing the interaction. How do you meet the task this time? Do you come up with different similarities than in the 'sensinground'? What might these similarities tell you about the interaction? Code your records for not mixing them up inadvertently.

\section{Fourth round (optional): ConFiguration}

Taking a little more time, you could do a conFiguration of one of the similarities found in the matrix, and even do an exchange of your matrix with another group. For this you will need to run the exploration with 6 people. The conFiguration follows the example of contact improvisation described in 4.2 in the paper. The similarities detected in the matrix now turn into 'interim findings'. You can use the following formats:

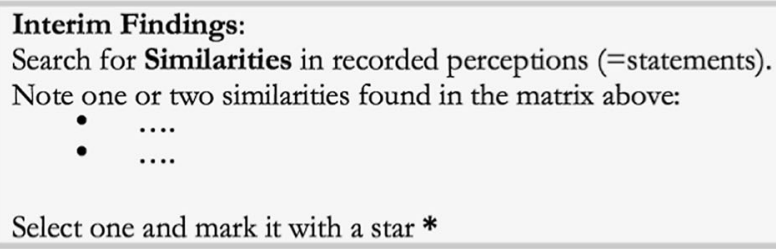

\section{Perceptional ConFiguration.}

Repeat the practice sequence (interaction) while producing the selected similarity additionally on purpose (=conFiguration: conFiguring perception)

\section{From experience to understanding}

\section{Findings revisited}

After having produced the selected similarity use this embodied experience to refine the similarity:

-....

Optional - Exchange of materials between two groups:

Group X works on other group Y's notated perceptions (coloured matrix group Y). Group Y works on group X's material.

\section{Interim Findings (group $\mathrm{X}$ on group $\mathrm{Y} /$ resp. group $\mathrm{Y}$ on group $\mathrm{X}$ ):}

Search for Similarities in statements. Note one or two similarities found in the matrix of the other group

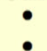

Select one and mark it with a star* 
Then repeat your own group's first interaction while producing the above selected similarity additionally on purpose (= conFiguration).

\section{Findings revisited}

After having produced the selected similarity use this embodied experience to refine the similarity:

$\ldots$

First share your experience among your group. What was different in the exchange experience working on the other group's (the 'foreign') material compared to the first process with your own material? Then sit together with the other group and present to each other what you have done. Compare your previous interim findings $(=$ similarities) on your own process with the other group having operated with your material. Do they resemble each other or diverge? In which process - the final one (= refinement) or in the interim step? Or in both? If yes: in which regard?

Finally, compose the entire outcome on the interaction investigated. This generated data on your embodied experiences and reflections documents all the steps, which thus can be traced back to its beginnings. New aspects have emerged as a result of questioning and comparison. What does it tell you on the interaction now?

\section{References}

Bachrach, A., Fontbonne, Y., Joufflineau, C., \& Ulloa Fulgeri, J.L. (2015). Audience entrainment during live contemporary dance performance: Physiological and cognitive measures. Frontiers in Human Neuroscience, 9. doi:10.3389/fnhum.2015.00179.

Bateson, M. C. (1979). 'The epigenesis of conversational interaction': A personal account of research development. In M. Bullowa (Ed.), Before speech. London: Cambridge University Press.

Beck, U., \& Beck-Gernsheim, E. (1996). Individualization and 'Precarious Freedoms': Perspectives and controversies of a subject-oriented sociology. In P. Helas, S. Lash, \& P. Morris (Eds.), Detraditionalisation. Critical reflections on authority and identity. Cambridge: Blackwell.

Beebe, B., \& Lachmann, F. M. (1998). Co-constructing inner and relational processes. Self- and mutual regulation in infant research and adult treatment. Psychoanalytic Psychology, 15, 480-516.

Behrends, A., Müller, S., \& Dziobek, I. (2012). Moving in and out of synchrony: a concept for a new intervention fostering empathy through interactional movement and dance. The Arts in Psychotherapy, 39, 107-116.

Berger, P., \& Luckmann, T. (1966). The social construction of knowledge: a treatise in the sociology of knowledge. Soho: Open Road Media.

Böhle, F., Bolte, A., Huchler, N., Neumer, J., Porschen-Hueck, S., \& Sauer, S. (2014). Vertrauen und Vertrauenswürdigkeit. Arbeitsgestaltung und Arbeitspolitik jenseits formeller Regulierung. Heidelberg: Springer.

Bolte, K. M. (1997). 'Subjektorientierte Soziologie' im Rahmen soziologischer Forschung - Versuch einer Verortung. In G. G. Voß \& H. Pongratz (Eds.), Subjektorientierte Soziologie (pp. 31-40). Opladen: Leske + Budrich. 
Bruner, J. (1990). Acts of meaning. Cambridge: Harvard University Press.

Buchanan, P.A. (2012). The Feldenkrais Method® of Somatic Education. In A Compendium of Essays on Alternative Therapy, ed A. Bhattacharya (InTech). Available online at: http://www.intechopen.com/books/ a-compendium-of-essays-on-alternative-therapy/the-feldenkrais-method-of-somatic-education. Accessed Apr 132014.

Bullowa, M. (1979). Before speech. The beginning of interpersonal communication. Cambridge: Cambridge University Press.

Clénin, D. \& Pieper, B. (2015) Compilation of PRISMA Workshops and Presentations in Practice and Science since 2001. PRISMA Projects Munich-Berne. http://www.barbarapieper.de/downloads/PRISMA\% 20Compilation_Workshops_Presentations\%20since\%202001_2015\%2012\%2005.pdf.

Cuffari, E.C. (2014). Keep meaning in conversational coordination. Frontiers in Psychology, 5(1397). doi:10. 3389/fpsyg.2014.01397.

Cuffari, E., Di Paolo, E., \& De Jaegher, H. (2015). From participatory sense-making to language: there and back again. Phenomenology and the Cognitive Sciences, 14(4), 1089-1125. doi:10.1007/s11097-014-9404-9.

De Jaegher, H. (2009). Social understanding through direct perception? Yes, by interacting. Consciousness and Cognition, 18, 535-542. doi:10.1016/j.concog.2008.10.007.

De Jaegher, H. (2013). Embodiment and sense-making in autism. Frontiers in Integrative Neuroscience, 7, 15. doi:10.3389/fnint.2013.00015.

De Jaegher, H. (2015). How we affect each other. Michel Henry's 'pathos-with' and the enactive approach to intersubjectivity. Journal of Consciousness Studies, 22(1-2), 112-132.

De Jaegher, H. (2016). Intersubjectivity in the study of experience. Constructivist Foundations.

De Jaegher, H., \& Di Paolo, E. (2007). Participatory sense-making: an enactive approach to social cognition. Phenomenology and the Cognitive Sciences, 6(4), 485-507.

De Jaegher, H., Di Paolo, E. A., \& Gallagher, S. (2010). Can social interaction constitute social cognition? Trends in Cognitive Sciences, 14(10), 441-447. doi:10.1016/j.tics.2010.06.009.

De Jaegher, H., Peräkylä, A., \& Stevanovic, M. (2016). The co-creation of meaningful action: bridging enaction and interactional sociology. Philosophical Transactions of the Royal Society B-Biological Sciences. doi:10.1098/rstb.2015.0378.

Delafield-Butt, J.T. \& Trevarthen, C. (2015). The ontogenesis of narrative: from purposeful movements to shared meaning-making. Frontiers in Psychology, 6. doi:10.3389/fpsyg.2015.01157.

Depraz, N., Varela, F. J., \& Vermersch, P. (2003). On becoming aware: a pragmatics of experiencing. Amsterdam: John Benjamins.

Di Paolo, E. (2015). Interactive time-travel: on the intersubjective retro-modulation of intentions. Journal of Consciousness Studies, 22(1-2), 49-74.

Di Paolo, E.A., \& De Jaegher, H. (2012). The interactive brain hypothesis. Frontiers in Human Neuroscience, 6(163). doi: 10.3389/fnhum.2012.00163.

Di Paolo, E. A., Rohde, M., \& De Jaegher, H. (2010). Horizons for the enactive mind: Values, social interaction, and play. In J. Stewart, O. Gapenne, \& E. Di Paolo (Eds.), Enaction: toward a new paradigm for cognitive science (pp. 33-87). Cambridge: MIT Press.

Dickerson, P., Stribling, P., \& Rae, J. (2007). Tapping into interaction: how children with autistic spectrum disorders design and place tapping in relation to activities in progress. Gesture, 7, 271-303.

Donnellan, A., Hill, D.A., \& Leary, M.R. (2013). Rethinking autism: implications of sensory and movement differences for understanding and support. Frontiers in Integrative Neuroscience, 6(124). doi:10.3389/ fnint.2012.00124.

Dumas, G., Lachat, F., Martinerie, J., Nadel, J., \& George, N. (2011). From social behaviour to brain synchronization: review and perspectives in hyperscanning. IRBM, 32(1), 48-53. doi:10.1016/j.irbm. 2011.01.002.

Dumas, G., Laroche, J., \& Lehmann, A. (2014). Your body, my body, our coupling moves our bodies. Frontiers in Human Neuroscience, 8. doi:10.3389/fnhum.2014.01004.

Feldenkrais, M. (1947). Body and mature behaviour: a study of anxiety, sex, gravitation and learning. New York: International University Press.

Feldenkrais, M. (1972). Awareness through movement: easy-to-do health exercises to improve your posture, vision, imagination, and personal awareness. San Francisco: Harper \& Row.

Feldenkrais, M. (1981). The elusive obvious. Capitola: Meta Publications.

Froese, T., Gould, C., \& Seth, A. K. (2011). Validating and calibrating first- and second-person methods in the science of consciousness. Journal of Consciousness Studies, 18, 38-64.

Fuchs, T. (2000). Leib, Raum, Person: Entwurf einer phänomenologischen Anthropologie: Klett-Cotta.

Fuchs, T. (2007). Psychotherapy of the lived space: a phenomenological and ecological concept. American Journal of Psychotherapy, 61, 423-439. 
Fuchs, T. (2015). Pathologies of intersubjectivity in autism and schizophrenia. Journal of Consciousness Studies, 22(1-2), 191-214.

Fuchs, T., \& De Jaegher, H. (2009). Enactive Intersubjectivity: participatory sense-making and mutual incorporation. Phenomenology and the Cognitive Sciences, 8(4), 465-486. doi:10.1007/s11097-009-9136-4.

Fuchs, T., \& Koch, S.C. (2014). Embodied affectivity: on moving and being moved. Frontiers in Psychology, 5. doi: 10.3389/fpsyg.2014.00508.

Fusaroli, R., Rączaszek-Leonardi, J., \& Tylén, K. (2014). Dialog as interpersonal synergy. New Ideas in Psychology, 32, 147-157.

Galbusera, L., \& Fuchs, T. (2014). Embodied understanding: discovering the body from cognitive science to psychotherapy. In Mind Italia, $\mathrm{V}, 1-6$.

Gallagher, S. (1997). Mutual enlightenment: recent phenomenology and cognitive science. Journal of Consciousness Studies, 4(3), 195-214.

Gallagher, S. (2005). How the body shapes the mind. Oxford: Oxford University Press.

Gallagher, S., \& Zahavi, D. (2008). The phenomenological mind: an introduction to philosophy of mind and cognitive science. London: Routledge.

Gendlin, E.T. (1962/1997). Experience and the creation of meaning: a philosophical and psychological approach to the subjective. Evanston: Northwestern University Press.

Grunwald, M., \& Beyer, J. (2010). Haptics - The science of touch. Basics and applications. In D. Madalina (Ed.), Senses and the City. An interdisciplinary view of urban sensescapes (pp. 113-135). Berlin: LIT Verlag.

Gurwitsch, A. (1979). Human encounters in the social world. Pittsburgh: Duquesne University Press.

Harrison, J. E., \& Baron-Cohen, S. (1997). Synaesthesia: an introduction. In S. Baron-Cohen \& J. L. Harrison (Eds.), Synaesthesia (pp. 3-16). London: Blackwell.

Heavey, C. L., \& Hurlburt, R. T. (2008). The phenomena of inner experience. Consciousness and Cognition, 17(3), 798-810. doi:10.1016/j.concog.2007.12.006.

Hobson, R. P. (2002). The cradle of thought. London: Macmillan.

Hobson, R. P., \& Lee, A. (1998). Hello and goodbye: a study of social engagement in autism. Journal of Autism and Developmental Disorders, 28, 117-127.

Høffding, S., \& Martiny, K. (2015, 2016). Framing a phenomenological interview: what, why and how. Phenomenology and the Cognitive Sciences, 1-26. doi:10.1007/s11097-015-9433-z.

Hubbard, P., \& Kitchin, R. (Eds.). (2004). Key thinkers on space and place. London: Sage.

Hurlburt, R., Heavey, C. L., \& Bensaheb, A. (2009). Sensory awareness. Journal of Consciousness Studies, 16(10-12), 231-251.

Ihde, D. (2012). Experimental phenomenology. Multistabilities (2nd ed.). New York: SUNY Press.

Jack, A. I., \& Roepstorff, A. (2002a). Introspection and cognitive brain mapping: from stimulus-response to script-report. Trends in Cognitive Sciences, 6(8), 333-339.

Jack, A. I., \& Roepstorff, A. (2002b). The "measurement problem" for experience: damaging flaw or intriguing puzzle? Response to Schooler. Trends in Cognitive Sciences, 6(9), 372-374.

Jack, A.I., \& Roepstorff, A. (2003). Why trust the subject? Journal of Consciousness Studies, 10(9-10).

Johnson, M. (2007). The meaning of the body. Aesthetics of human understanding. Chicago: University of Chicago Press.

Jonas, H. (2002). Wissenschaft as personal experience. The Hastings Center Report, 32(4), $27-35$.

Jurczyk, K., Voß, G. G., \& Weihrich, M. (2016). Conduct of everyday life in subject-oriented sociology: Concept and empirical research. In E. Schraube \& C. Højholt (Eds.), Psychology and the conduct of everyday life (pp. 34-66). London and New York: Routledge.

Kimmel, M., Irran, C., \& Luger, M.A. (2014). Bodywork as systemic and inter-enactive competence: participatory process management in Feldenkrais Method \& Zen Shiatsu. Frontiers in Psychology, 5. doi:10.3389/fpsyg.2014.01424.

Kordeš, U. (2016). Going beyond theory: constructivism and empirical phenomenology. Constructivist Foundations, 11(2).

Küchenhof, J. (2014). Die Phänomenologie des Fremden als Grundlage psychiatrisch-psychotherapeutischen Handelns. In T. Fuchs, T. Breyer, S. Micali, \& B. Wandruszka (Eds.), Das leidende Subjekt. Phänomenologie als Wissenschaft der Psyche. Freibung: Karl Alber.

Laroche, J., Berardi, A.-M., \& Brangier, E. (2014). Embodiment of intersubjective time: relational dynamics as attractors in the temporal coordination of interpersonal behaviors and experiences. Frontiers in Psychology, 5. doi:10.3389/fpsyg.2014.01180.

Le Van Quyen, M., \& Petitmengin, C. (2002). Neuronal dynamics and conscious experience: an example of reciprocal causation before epileptic seizures. Phenomenology and the Cognitive Sciences, 1(2), 169-180. doi:10.1023/a:1020364003336. 
Lechner, F. J. (1991). Simmel on social space. Theory, Culture, and Society, 8(3), 195-201.

Löw, M. (2008). The constitution of space. The structuration of spaces through the simultaneity of effect and perception. European Journal of Social Theory, 11(1), 25-49.

Maiese, M. (2016). Embodied selves and divided minds. Oxford: Oxford University Press.

Malloch, S., \& Trevarthen, C. (Eds.). (2009). Communicative musicality: exploring the basis of human companionship. Oxford: Oxford University Press.

Martin, L.A.L., Koch, S.C., Hirjak, D., \& Fuchs, T. (2016). Overcoming disembodiment: The effect of movement therapy on negative symptoms in schizophrenia - A multicenter randomized controlled trial. Frontiers in Psychology, 7. doi:10.3389/fpsyg.2016.00483.

Merleau-Ponty, M. (1945/2012). Phenomenology of perception (D. A. Landes, Trans.). London: Routledge.

Novack, C. J. (1990). Sharing the dance: contact improvisation and American culture. Madison: University of Wisconsin Press.

Noy, L., Levit Binnun, N., Alon, U., \& Golland, Y. (2015). Being in the zone: physiological markers of togetherness in joint improvisation. Frontiers in Human Neuroscience, 9. doi: 10.3389/fnhum.2015. 00187.

Payne, P., Levine, P.A., \& Crane-Godreau, M.A. (2015). Somatic experiencing: using interoception and proprioception as core elements of trauma therapy. Frontiers in Psychology, 6. doi:10.3389/fpsyg.2015. 00093.

Petitmengin, C. (Ed.). (2009). Ten years of viewing from within: the legacy of F.J. Varela. London: Imprint.

Petitmengin, C., \& Bitbol, M. (2009). Listening from within. Journal of Consciousness Studies, 16(10-1), 363-404.

Petitot, J., Varela, F. J., Pachoud, B., \& Roy, J.-M. (Eds.). (1999). Naturalizing phenomenology: issues in contemporary phenomenology and cognitive science. Stanford: Stanford University Press.

Pfeiffer, U. J., Schilbach, L., Timmermans, B., et al. (2014). Why we interact: on the functional role of the striatum in the subjective experience of social interaction. NeuroImage, 101, 124-137.

Pieper, B. (1983). Subjektorientierung als Forschungsverfahren - vorgestellt am Beispiel häuslicher Arbeit. In K.M, Bolte, E. Treutner. (Eds.), Subjektorientierte Arbeits- und Berufssoziologie (pp. 294-323). Frankfurt a.M./New York: Campus.

Pieper, B. (1997). Subjektorientierung jenseits des Zaunes: Anregungen für die Praxis - Ideen aus der Praxis (Feldenkrais-Methode). In G. G. Voß \& H. Pongratz (Eds.), Subjektorientierte Soziologie. Karl Martin Bolte zum siebzigsten Geburtstag (pp. 127-154). Leske und Budrich: Leverkusen. http://www. barbarapieper.de/downloads/BolteLeske-Verlag.pdf.

Pieper, B. (2012). Embodied experiences related to trust-building in every day intersubjective contexts. Munich: Institut für Sozialwissenschaftliche Forschung e.V. http://www.verred.de/files/reader_verred_ workshop juli 2012.pdf.

Pieper, B., \& Clénin, D. (2012). Embodied perception of self and others in social action. A research perspective combining theory and practice. unofficial translation of Pieper, B., \& Clénin, D. (2010). Verkörperte Selbst- und Fremdwahrnehmung sozialen Handelns. Eine leib-orientierte praktischtheoretische Forschungsperspektive. In F. Böhle, M. Weihrich (Eds.), Die Körperlichkeit sozialen Handelns. Soziale Ordnung jenseits von Normen und Institutionen. transcript Verlag, Bielefeld. https:// tesis2012.files.wordpress.com/2012/05/pieper_clenin_embodied-perception1.pdf.

Pieper, B., \& Weise, S. (1997). Feldenkrais. Tasks, Activities, Development of a New Profession Vocational Profile commissioned by the German Feldenkrais Guild, Bibliothek der Feldenkrais-Gilde e.V. Nr. 12, Published by Karin Engels-Maurer and Christoph Goertz Translated by Ilana Nevill. http://www. barbarapieper.de/downloads/pieper_weise_vocational_profile1996_eng1_1997.pdf.

Polanyi, M. (1958). Personal knowledge. Towards a post critical epistemology. London: Routledge and Kegan Paul.

Polanyi, M. (1967). The tacit dimension. Garden City: Anchor Books.

Pongratz, H., \& Voß, G. G. (Eds.). (1997). Subjektorientierte Soziologie. Opladen: Leske + Budrich.

Ramseyer, F., \& Tschacher, W. (2008). Synchrony in dyadic psychotherapy sessions. In S. Vrobel, O. E. Roessler, \& T. Marks-Tarlow (Eds.), Simultaneity: temporal structures and observer perspectives. Singapore: World Scientific.

Ratcliffe, M. (2007). Rethinking commonsense psychology: a critique of folk psychology, theory of mind and simulation. Hampshire/New York: Palgrave Macmillan.

Reddy, V. (2008). How infants know minds. Cambridge: Harvard University Press.

Reddy, V., \& Morris, P. (2004). Participants don't need theories: knowing minds in engagement. Theory \& Psychology, 14(5), 647-665.

Schilbach, L., Timmermans, B., Reddy, V., Costall, A., Bente, G., Schlicht, T., \& Vogeley, K. (2013). Towards a second-person neuroscience. Behavioral and Brain Sciences, 36, 393-462. 
Sheets-Johnstone, M. (1999). The primacy of movement. Amsterdam: John Benjamins.

Sheets-Johnstone, M. (2015). Embodiment on trial: a phenomenological investigation. Continental Philosophy Review, 48(1), 23-39. doi:10.1007/s11007-014-9315-z.

Shusterman, R. (2008). Body consciousness. A philosophy of mindfulness and somaesthetics. New York: Cambridge University Press.

Simmel, G. (1908). Der Raum und die räumlichen Ordnungen der Gesellschaft. In G. Simmel (Ed.), Soziologie. Untersuchungen über die Formen der Vergesellschaftung, p. 460 - 526 (Chapter IX). Berlin: Duncker \& Humblot.

Stern, D.N. (1977/2002). The first relationship: infant and mother. London, Harvard University Press.

Stern, D.N. (1985/1998). The interpersonal world of the infant: a view from psychoanalysis and developmental psychology. New York, Basic Books.

Stern, D.N. (2004). The present moment in psychotherapy and everyday life (Norton Series on Interpersonal Neurobiology): WW Norton \& Company.

Sterponi, L., \& Fasulo, A. (2010). "How to go on": intersubjectivity and progressivity in the communication of a child with autism. ETHOS, 38(1), 116-142.

Sterponi, L., \& Shankey, J. (2014). Rethinking echolalia: repetition as interactional resource in the communication of a child with autism. Journal of Child Language, 41(2), 275-304.

Stribling, P., Rae, J., Dickerson, P., \& Dautenhahn, K. (2005-06). "Spelling it out": the design, delivery and placement of 'echolalic' utterances by a child with an autism spectrum disorder. Issues in Applied Linguistics, 15(1):3-32.

Stribling, P., Rae, J., \& Dickerson, P. (2007). Two forms of spoken repetition in a girl with autism. International Journal of Language and Communication Disorders, 42, 427-444.

Thompson, E. (2001). Empathy and consciousness. Journal of Consciousness Studies, 8, 1-32.

Thompson, E. (2005). Empathy and human experience. In J. Proctor (Ed.), Science, religion, and the human experience (pp. 262-286). New York: Oxford University Press.

Thompson, E. (2007). Mind in life: biology, phenomenology, and the sciences of mind. Cambridge: MA, Harvard University Press.

Timmermans, B. \& Schilbach, L. (2014). Investigating alterations of social interaction in psychiatric disorders with dual interactive eye tracking and virtual faces. Frontiers in Human Neuroscience, 8. doi:10.3389/ fnhum.2014.00758.

Trevarthen, C. (1977). Descriptive analyses of infant communicative behaviour. In H. R. Schaffer (Ed.), Studies in mother-infant interaction. London: Academic.

Trevarthen, C., \& Aitken, K. J. (2001). Infant intersubjectivity: research, theory, and clinical applications. Journal of Child Psychology and Psychiatry, 42(1), 3-48.

Van Manen, M. (1990). Researching lived experience: human science for an action sensitive pedagogy. New York: Suny Press.

Varela, F. J. (1996). Neurophenomenology: a methodological remedy for the hard problem. Journal of Consciousness Studies, 3(4), 330-349.

Varela, F. J., \& Shear, J. (1999a). The view from within. Exeter: Imprint Academic.

Varela, F. J., \& Shear, J. (1999b). First-person methodologies: what, why, how? Journal of Consciousness Studies, 6(2-3), 1-14.

Varela, F. J., Thompson, E., \& Rosch, E. (1991). The embodied mind: cognitive science and human experience (6th ed.). Cambridge: MIT Press.

Vermersch, P. (1999). Introspection as practice. Journal of Consciousness Studies, 6(2-3), 17-42.

Verrel, J., Almagor, E., Schumann, F., Lindenberger, U., \& Kühn, S. (2015). Changes in neural resting state activity in primary and higher-order motor areas induced by a short sensorimotor intervention based on the Feldenkrais method. Frontiers in Human Neuroscience, 9. doi:10.3389/fnhum.2015.00232.

Watzlawick, P., Bavelas, J. B., Jackson, D. D. \& O’hanlon, B. (2011). Pragmatics of human communication: a study of interactional patterns, pathologies and paradoxes, WW Norton \& Company. 